\title{
Ablation and Thermal Response Property Model Validation for Phenolic Impregnated Carbon Ablator
}

\author{
F.S. Milos ${ }^{*}$ and Y.-K. Chen ${ }^{\dagger}$ \\ NASA Ames Research Center, Moffett Field, CA 94035-1000
}

\begin{abstract}
Phenolic Impregnated Carbon Ablator was the heatshield material for the Stardust probe and is also a candidate heatshield material for the Orion Crew Module. As part of the heatshield qualification for Orion, physical and thermal properties were measured for newly manufactured material, included emissivity, heat capacity, thermal conductivity, elemental composition, and thermal decomposition rates. Based on these properties, an ablation and thermal-response model was developed for temperatures up to $3500 \mathrm{~K}$ and pressures up to $100 \mathrm{kPa}$. The model includes orthotropic and pressure-dependent thermal conductivity. In this work, model validation is accomplished by comparison of predictions with data from many arcjet tests conducted over a range of stagnation heat flux and pressure from 107 $\mathrm{W} / \mathrm{cm}^{2}$ at $2.3 \mathrm{kPa}$ to $1100 \mathrm{~W} / \mathrm{cm}^{2}$ at $84 \mathrm{kPa}$. Over the entire range of test conditions, model predictions compare well with measured recession, maximum surface temperatures, and indepth temperatures.
\end{abstract}

\section{Nomenclature}

A, B, C, D = four thermocouple placement options

$E \quad=$ fractional error in recession

I, II, III = three model geometry options

$\Delta S \quad=$ centerline recession, $\mathrm{mm}$

$X, Y \quad=$ Cartesian coordinates perpendicular to $Z, \mathrm{~cm}$

$Z \quad=$ Cartesian coordinate parallel to the axis of the geometry, $\mathrm{cm}$

\section{Introduction}

Dhenolic impregnated Carbon Ablator (PICA) ${ }^{1}$ is one of the lightweight ceramic charring ablators developed at P NASA Ames Research Center in the 1990's. PICA was the heatshield material on the Stardust sample-return capsule, ${ }^{2}$ which is to date the fastest man-made Earth-entry vehicle. PICA is the forebody heatshield material for both the Mars Science Laboratory and the SpaceX Dragon vehicle, and it is one of two candidate materials for the Orion Crew Module.

The Orion thermal protection system (TPS) advanced development project conducted extensive thermal, mechanical, and general property testing of newly manufactured PICA. Based on test results, the PICAv3.3 material property model $^{3}$ was developed for use with the analysis tools FIAT $^{4}$ and TITAN $^{5}$ that predict ablation, pyrolysis, and thermal conduction in one and two dimensions, respectively. These analysis tools and the PICAv3.3 model are currently being used for analysis of ground tests as well as for thermal analysis and sizing of PICA tiles for flight applications on Orion, ${ }^{6}$ Mars Science Laboratory, and Dragon.

A large number of arcjet tests were performed to acquire data on PICA thermal and ablative performance over a wide range of aerothermal conditions applicable to Orion low-Earth-orbit and Lunar-return entries. Concurrent with the aforementioned testing, the PICAv3.3 model was validated by comparison of numerical predictions with this large database of arcjet test data. The purpose of this work is to document a representative portion of these validation studies, and in particular to demonstrate to what extent the analyses agree or disagree with the available data.

\footnotetext{
*Aerospace Engineer, Thermal Protection Materials and Systems Branch, MS 234-1. Senior Member AIAA.

${ }^{\dagger}$ Aerospace Engineer, Thermal Protection Materials and Systems Branch, MS 234-1. Member AIAA.
} 


\section{Material Properties}

PICA is a composite material made from a low density, rigid, carbon fiber insulation (named Fiberform ${ }^{\circledR}$, from Fiber Material, Inc.) impregnated with a commercial phenolic resin. The density of both components may vary depending on the material processing employed. For application to the Orion heatshield, large quantities of PICA were needed. Therefore, the manufacturing capability was scaled up and tailored to produce consistent material in a specific density range. The Orion TPS advanced development project conducted extensive property testing of newly manufactured PICA. For virgin PICA, in general, multiple samples of material from different manufacturing lots were tested. Some properties were measured for arcjet and furnace-generated chars and also for the Fiberform ${ }^{\circledR}$ substrate. This testing provided a database of material properties for PICA model development.

Virgin and char density and elemental composition were measured at room temperature. The emissivity was derived from spectral reflectance measurements of virgin material and of arcjet chars. Heat capacity and thermal conductivity were measured over a range of temperatures up to approximately $500 \mathrm{~K}$. The heat capacity of virgin and char were consistent with known values for graphitic carbon and phenolic polymer. The thermal conductivity was found to be strongly orthotropic and also weakly pressure dependent, because the material is porous. Thermal decomposition was measured at three heating rates and then curve fit using a three-reaction model. Pyrolysis gas enthalpy was calculated using the Multicomponent Ablation Thermochemistry (MAT) $\operatorname{code}^{7}$ and assuming a transition from frozen composition at low temperature to equilibrium composition at high temperature. Equilibrium thermochemical ablation tables were calculated using MAT for varying atmospheres (nitrogen-oxygen and air-argon mixtures) applicable to arcjet and flight environments. Some high temperature thermal properties were estimated. Specifically, the char heat capacity was assumed to be that of graphitic carbon. Also, the high temperature thermal conductivity was first estimated and then adjusted at three temperatures by comparison of one-dimensional FIAT model predictions with arcjet near-surface thermocouple data in a manner similar to that described in Reference 8 .

Material properties of high-performance ablators are subject to export-control restrictions. Therefore, the PICAv3.3 ablation and thermal property model and the data upon which it is based cannot be included in this paper. However, this information is thoroughly documented in Reference 3, which is available to qualified U.S. persons.

\section{Arcjet Models and Test Conditions}

Figure 1 shows the calorimeter and model shape used in recent arcjet testing. This nose radius equals the diameter, the shoulder radius is $1 / 16$ of the diameter, and the sides are cylindrical. The primary advantage of this "iso-q" geometry, compared with the more traditional flat-faced geometry, is that in the ARC arcjets the heat flux distribution is relatively constant over most of the front face. A typical computational fluid dynamics (CFD) calculation for a $10.16 \mathrm{~cm}$ diameter iso-q shape is provided in Figure 2. This solution was calculated using the DPLR code. ${ }^{9}$ The calculated heat flux varies only $10 \%$ on the front face. The heat flux on the cylindrical side, as shown by the green portion of the curve, is $10 \%$ to $20 \%$ of the stagnation point value for $5 \mathrm{~cm}$ beyond the shoulder. This magnitude of heating is not negligible; therefore, it is to be expected that a non-negligible heat load passes in through the cylindrical sides of the model.

Figure 3 presents a cross section of a PICA sample that was tested for 200 seconds and which experienced $13 \mathrm{~mm}$ of recession at the centerline. The red curve shows the initial unablated shape. The sidewall heating had sufficient magnitude to produce a substantial char depth and some recession, as evidenced by the slightly canted sides. Nevertheless, the ablated shape is comparable to the initial shape.

Figure 4 contains cross-sectional drawings of Types I, II, and III of iso-q arcjet models used in this study. All models had $10.16 \mathrm{~cm}$ diameter, except for one condition at $970 \mathrm{~W} / \mathrm{cm}^{2}$ where the diameter was $7.62 \mathrm{~cm}$. In general, the exposed surface was machined PICA, and all unexposed PICA surfaces were sealed or bonded to adjacent materials using RTV-560 adhesive. Small spaces may be air gaps or partially filled with various adhesives. The LI-2200 is an insulative silica-fiber tile material. Type-I models are uninstrumented and were used in some initial screening tests. Most tests used Type-II models. For heat fluxes above $700 \mathrm{~W} / \mathrm{cm}^{2}$ the Type-III models with a silicaphenolic collar were used, because the sidewall heating is too high for the LI-2200 tile, which would melt excessively.

Most models of Types II and III contained a press-fit plug with five thermocouples (TCs), as illustrated in Figure 5. The plug diameter was $2.54 \mathrm{~cm}$. The two thermocouples closest to the surface were type-R, and the three deeper thermocouples were type-K. Thermocouple wire with $0.25 \mathrm{~mm}$ diameter was inserted into $0.30 \mathrm{~mm}$ holes drilled perpendicular to the axis. The thermocouple junctions were centered at the axis. Grooves on the sides of the plug accommodated ceramic sleeves for the thermocouple wires. This installation method, with bare sensor wires 
approximately parallel to the heated surface, and with wire length-to-diameter ratio of at least 25:1 on each side of the TC junction, minimizes the measurement error due to temperature gradients along the length of the wires. ${ }^{10}$

A few models also had off-axis thermocouples at two depths at locations depicted in Figure 6. The off-axis thermocouples were installed using curved plugs that enabled sufficient lengths of thermocouple wire to be placed in concentric rings at various radii from the axis in a manner consistent with the ASTM standard. ${ }^{10}$ These thermocouples were unsheathed type-K with $0.25 \mathrm{~mm}$ diameter. Owing to spatial constraints for installation, thermocouples could not be placed at all ten locations within a single model. Some models contained thermocouples at locations 1 to 5 , whereas others contained thermocouples at locations 6 to 10. Figure 7 presents X-ray images of an arcjet model with off-axis thermocouples. The thermocouple junctions are indicated by red dots. The thermocouples are not coplanar, and location 10 had three thermocouples located at different circumferential angles.

Overall, there were four different nominal placements for the thermocouples, as denoted by letters A to D in Table 1. For placements A to $C$ the nominal spacing for axial thermocouples TC1 to TC4 was $0.381 \mathrm{~cm}$. Placement A with TC1 close to the surface was intended for use in the lowest heat flux environments. Placement $\mathrm{C}$, with the deepest thermocouples, was intended for use in the highest heat flux environments. Most models used placement B, which had intermediate thermocouple depths. Thermocouple placement option D includes the off-axis thermocouples that were used in two tests that will be thoroughly discussed in the Model Validation section. X-ray images of all pre-test models confirmed that thermocouples were installed within $\pm 0.02 \mathrm{~cm}$ of the nominal locations.

Arcjet tests were conducted in the Aerodynamic Heating Facility (AHF) ${ }^{11}$ and Interaction Heating Facility $(\mathrm{IHF})^{12}$ at NASA ARC and in the TP2 facility at NASA JSC. For all test conditions multiple runs and multiple swing arms were used to obtain calibration measurements of stagnation pressure and cold-wall heat flux, and if possible, temperature response from multiple arcjet models with the same or different exposure durations. At the end of the exposure, the model was removed from the arcjet flowfield and held in a low-pressure environment during a cool-down period of several hundred seconds.

The stagnation pressure and heat flux were measured using a combination slug-calorimeter/pitot-pressure device (Figure 1) that had the same external shape as the TPS samples to be tested. ${ }^{13}$ The calorimeter is inserted into the arcjet flow for approximately 3 seconds. Because the arcjet flow swirls and is not totally steady, there is natural variation in the stagnation measurements obtained from a short exposure even within the same arcjet run. Greater variation is seen on a run-to-run basis. The average stagnation measurements may not be representative of the average values experienced by any specific TPS sample that is tested for a longer time. The pressure measurements have less variability than the heat flux measurements. Based on previous experience with the arcjet facilities, we consider the uncertainty of the stagnation pressure to be less than $\pm 5 \%$, and the uncertainty in heat flux to be between $\pm 10 \%$ and $\pm 15 \%{ }^{8}$

In the ARC facilities argon is used to protect the upstream electrode, the main air is added along the length of the arcjet column, and additional air (called add air) may be injected after the downstream electrode. In the AHF facility there is a mixing chamber for add air between the downstream electrode and the nozzle. There is no such mixing chamber in the IHF. The total argon mass fraction in the flowfield depends on the three gas flowrates and the extent of add air mixing into the core of the flowfield.

PICA models were exposed to eighteen different test conditions, listed in Table 2. Shaded rows in Table 2 indicate the initial screening tests that used uninstrumented models. For nine conditions there were two exposure durations that are designated as cases $a$ and $b$, in order of increasing exposure duration. Condition 18 is a dual-pulse test where the model was tested at one condition, removed from the flow for cool down, then reinserted for a second exposure at different arcjet conditions. Two columns are provided for the argon mass fraction at the centerline. The first column is the minimum argon fraction that is obtained if the add air is perfectly mixed throughout the flowfield. The second column is the maximum argon fraction that is obtained if the add air does not mix into the hot core of the flowfield. In both cases we assume that the argon and main air are thoroughly mixed.

The ARC stagnation conditions are plotted as black dots in Figure 8. The stagnation heat flux and pressure ranges are 107 to $1102 \mathrm{~W} / \mathrm{cm}^{2}$ and 2.3 to $84.4 \mathrm{kPa}$, respectively. In general, the heat flux and pressure increase concurrently as the test conditions become more severe. Hence, the points cluster near the diagonal of the figure. However, add air may be used to increase the pressure and to reduce the heat flux. If the add air flow is sufficiently high, then this process can produce points that lie significantly to the right of the diagonal corresponding to conditions 3,5 , and 7 of Table 2 .

In the JSC facility, nitrogen is used to protect the upstream electrode; then both oxygen and nitrogen may be injected along the length of the arcjet to obtain a desired ratio of total oxygen to total nitrogen. The models were tested at four test conditions provided in Table 3 . The stagnations conditions were approximately $412 \mathrm{~W} / \mathrm{cm}^{2}$ at 18.3 
$\mathrm{kPa}$ for all four conditions, but the ratio of total nitrogen to total oxygen varied from $0 \%$ to $30 \%$ by mass. The oxygen fraction at the centerline depends on the extent of gas mixing. The JSC conditions are shown as a cluster of four red dots in Figure 8.

Both Table 2 and Table 3 contain two columns for enthalpy. The facility enthalpy is a value estimated from laminar flow heat transfer correlations based on the measured stagnation pressure and the cold-wall (calorimeter) heat flux. ${ }^{14}$ The DPLR column provides the centerline enthalpy of the calculated flowfield. These values differ in most cases by $3 \%$ to $10 \%$. The CFD-based enthalpy is considered to be the more reliable quantity and was used for all calculations presented in this work.

Table 4 provides a summary of all models tested, the thermocouple placement option (A to D or none), the measured centerline recession, and the maximum surface temperature. All PICA models were manufactured with the low conductivity direction parallel to the axis of symmetry. A total of 69 models were tested at 22 flow conditions. Forty-six of the models were instrumented with thermocouple plugs and tested at 17 conditions.

\section{Model Instrumentation and Measurements}

Surface temperature was estimated using two single-wavelength (one color) optical pyrometers and one dualwavelength (two color) pyrometer. Raw pyrometer data were corrected for window and transmission losses, as applicable, and reported as a surface temperature. For the single-wavelength pyrometers, the data were corrected for temperature-dependent material emissivity. Owing to the high emissivity of charred PICA, this correction is relatively small and varies from $+1.1 \%$ at $2000 \mathrm{~K}$ to $+1.6 \%$ at $3500 \mathrm{~K}$. The intrinsic error of the one-color pyrometers after all corrections is estimated as $\pm 5 \%$, based on previous experience with the ARC arcjet facilities. For the two-color pyrometer, there is no emissivity correction. The intrinsic error depends on the ratio of the spectral emittance at the two sensing wavelengths. For example a $1 \%$ difference in emittance will result in an intrinsic error of about $\pm 7 \%$ at $3500 \mathrm{~K}$. For PICA the uncertainty is expected to be lower than this value.

In some tests, one or more pyrometers provided abnormal surface temperatures. There are several reasons why a pyrometer measurement may be too low. For example the pyrometer may not be focused exactly on the stagnation point of the model; furthermore, as the material ablates, the hot surface may move in or out of focus during the course of the experiment. In contrast, it is unlikely for a pyrometer to provide a temperature that is too high, except for the intrinsic error of the device. In the tests reported herein, for multiple samples tested at the same conditions, and excluding abnormal data, the corrected pyrometer temperatures were, in general, consistent within the assumed accuracy of $\pm 5 \%$. However, based on the preceding discussion, if multiple data sets are available, then the maximum pyrometer temperature may be the most reliable value.

In-depth temperatures were measured using multiple bare-wire type- $\mathrm{R}$ and type-K thermocouples installed as shown in Figures 5-7. The thermocouple wire diameter was $0.25 \mathrm{~mm}$. The thermocouple junctions were installed with at least $12.5 \mathrm{~mm}$ of wire aligned in a direction approximately parallel to the expected isotherm shape for axisymmetric heating. This installation method, with a length-to-diameter ratio of 25:1 on each side of the thermocouple junction, minimizes the error associated with temperature gradients in the wire. ${ }^{10}$ Thermal lag effects owing to the mass of the thermocouple are unavoidable but were minimized by using the thinnest practical wire diameter. With proper installation, temperature measurement errors for these in-depth thermocouple installations are estimated to be $\pm 5 \%$. The thermocouple depths and the arcjet exposure durations of most tests at ARC were selected to obtain a distribution of maximum temperatures at each test condition, with thermocouples located both in the char layer and in the pyrolysis zone. An additional goal was not to ablate more than one thermocouple, so that at least four thermocouples would provide data during the entire cool-down period.

Forty-six models, each containing five or more thermocouples, were tested. Very few thermocouples exhibited noisy or erratic response. The type- $\mathrm{R}$ and type-K thermocouples typically failed at temperatures near $2000 \mathrm{~K}$ and $1650 \mathrm{~K}$, respectively. In some models, the thermocouples continued to operate but provided poor data after a short exposure time near these temperature limits.

The use of unsheathed thermocouple wire can be problematic in dense carbonaceous materials owing to their significant electrical conductivity. However, both virgin and charred PICA have sufficiently low electrical conductivity to mitigate this potential issue for the thermocouple spacing employed in this work.

The total recession of the arcjet models was determined by two methods. In the first method, the pre- and posttest samples were placed on a support frame, and the vertical height $(Z)$ was measured at multiple locations in two perpendicular directions ( $\mathrm{X}$ and $\mathrm{Y}$ ) that pass through the axis of the model. The second method also employed a support frame; however, a fine-resolution laser scan of the vertical height was performed in the $\mathrm{X}$ and $\mathrm{Y}$ directions. 
For both methods, the pre-test model was marked so that the post-test sample could be aligned with the same X-Y orientation that was used for the pre-test measurements. The total recession was then calculated as the difference between the pre- and post-test $Z$ values. In either method there may be a slight $X-Y$ rotation or $Z$-axis offset between the pre- and post-test measurements. Therefore, it is difficult to determine small values of recession with precision, especially using the first method. In the central portion of the model, the recession values determined by the two methods agree, in general, to within an uncertainty of $\pm 0.5 \mathrm{~mm}$.

Three examples of laser scans of models tested over a range of heat fluxes are shown in Figure 9. The $X$ and $Y$ scans of pre-test and post-test models are shown in the upper row, and the difference between these curves is the recession plotted in the lower row. The lower figures also contain a black dot for the measured centerline recession with error bars. For some models the initial shape is asymmetric (although presumably within machining tolerance), and if the total recession is small, then this asymmetry is still visible in the post-test shape. This initial asymmetry is eliminated by the differencing operation used to calculate the recession. Nevertheless, the final recession distribution of a sample typically is asymmetric, and the amount of this asymmetry tends to increase with the severity of the test conditions and also with the use of add air in the IHF.

A constricted arcjet flowfield is swirling and unsteady, both spatially and temporally. Although we desire that the unsteadiness and asymmetry average out over the duration of the exposure, and in fact the flowfield is simulated as axisymmetric and steady, clearly this is not the case. Slightly asymmetric shapes result from asymmetric average heating distributions that are a natural result of an arcjet experiment.

Some post-test samples were cross sectioned, cleaned of cutting debris, and photographed from the direction perpendicular to the cut face. The photographs directly show the final ablated shape, and the color contours provide a qualitative measurement of the char depth. The color of partially charred PICA is not quantitatively related to density, because although the char is totally black, the virgin material varies in color. The material begins to develop a blackish hue when it is approximately $50 \%$ charred. ${ }^{15}$ The shape of color variations in the cross section photograph should correlate with density contours that indicate the depth of thermal penetration minus the amount of material ablated.

\section{Analysis Methodology}

The Navier-Stokes Computational Fluid Dynamics code developed at NASA Ames Research Center uses the state-of-the-art Data Parallel Line Relaxation (DPLR) method. DPLR is a Message Passing Interface-based full three-dimensional Navier-Stokes solver. DPLR was developed specifically for fast, robust, and accurate solution of hypersonic entry problems of interest to NASA. The DPLR code solves the time-dependent conservation equations of mass, momentum, and energy within a flowfield that may be in thermal and chemical nonequilibrium. For arcjet geometries the grid is subdivided in multiple blocks. The outer boundary of the stagnation point block is aligned with the shock, using an internal subroutine, and the cell Reynolds number equal to 1 is enforced. The Gauss-Seidel line relaxation method is modified to combine fast convergence for viscous flow with high efficiency on massively parallel computers. Although DPLR requires more memory than other codes, it reaches a steady-state solution in significantly less time than other data-parallel methods. The axisymmetric cases presented in this paper were computed on a UNIX cluster system containing 43 nodes.

The integration between DPLR and FIAT or TITAN is based on a loosely-coupled approach. All DPLR solutions are computed for an unblown and fully-catalytic surface. For each surface node of the solution, the recovery enthalpy and unblown heat transfer coefficient are calculated, and then these parameters and pressure are passed as boundary conditions to FIAT and/or TITAN. Surface thermochemical interactions and blowing effects are incorporated in these material-response codes by use of ablation tables, a surface energy balance with heat transfer coefficient, and a blowing reduction parameter. The blowing reduction parameter may be input as a function of time and location based on DPLR results; however, for the laminar flows considered in this work, a constant value of $1 / 2$ was used.

Both FIAT and TITAN contain a simple cool-down option for the surface energy balance. This cool-down boundary-condition option, which is used after the model is removed from the arcjet flow, allows the material to continue pyrolyzing and to radiate from its surface to the environment, but the surface ablation rate is set to zero. Most calculations were run to a total time of 700 seconds from the initial exposure to the arcjet.

One-dimensional FIAT calculations only require boundary conditions at the stagnation point as a function of time. For iso-q models tested at ARC, the relative shape change is small (cf. Figure 3), and the initial boundary conditions may be used for the entire duration of arcjet exposure. For some tests at JSC, the shape change was significant, and DPLR solutions were also calculated for the final ablated shape. Boundary conditions were 
generated for the final exposure time, and the FIAT calculations interpolated the boundary condition values for the initial and final times and shapes.

For both facilities, these one-dimensional calculations are accurate for stagnation point temperature and recession and for temperatures at axial near-surface thermocouples during the arcjet exposure period. The calculations are not accurate for in-depth temperatures or for long time (during cool down) owing to the effect of multidimensional heat conduction in PICA. A multidimensional analysis tool such as TITAN is required to obtain accurate predictions at greater times or depths, and furthermore, the orthotropic thermal conductivity of PICA must be taken into account. ${ }^{6}$

For the two-dimensional TITAN calculations, the small peak in heat flux predicted by DPLR on the shoulder for the unablated shape (Figure 2) causes the shoulder to change shape, which then alters the flowfield and heating distribution. The calculation cannot continue indefinitely with the original peaked heating profile, because within a few seconds the ablated surface would show an unrealistic indentation on the shoulder. To address this problem, TITAN calculations may be performed by two different approaches.

One approach ${ }^{16}$ for conducting the simulation is to start with the original shape and heating distribution, and then, as needed, to calculate a series of new DPLR solutions using grids for increasingly ablated shapes during the course of the TITAN run. The initial flow field and its associated surface heat flux and pressure are first computed by DPLR. For each surface point, the recovery enthalpy and the heat transfer coefficient are calculated, and then these parameters and pressure are passed as boundary conditions to TITAN. A time-accurate ablation and thermal response computation is performed by TITAN. When the maximum surface recession meets a pre-specified limit, TITAN stops its computation and outputs the location of the ablated surface. A new CFD grid is then generated for this ablated shape, and a new steady-state flow solution is calculated by DPLR. The recovery enthalpy and heat transfer coefficient are calculated for this new solution. The updated boundary conditions are input to TITAN for another run of time-accurate ablation and in-depth thermal response. This procedure is repeated until TITAN reaches the specified final time.

An alternative approach ${ }^{6}$ is to slightly modify the initial shape near the shoulder to eliminate the local maxima in heat flux. The modified shape is shown as a red curve in Figure 6. The modified shape has a more uniform heating distribution on the front face and no local maximum on the shoulder; however, the pressure drops off more rapidly with radius. The modified heating and pressure distributions, combined with the modified shoulder shape, allow a stable uncoupled calculation for the entire TITAN run at a fraction of the computational time required for the first approach. Reference 16 shows that this approximate method is quite accurate in computing in-depth temperature histories for iso-q shaped models at ARC. All TITAN results presented in this work used this second approach.

TITAN calculation for models of Type II and III use a two-block grid depicted in Figure 10. The grid extends several centimeters to the right of what is illustrated in the figure. The exterior block, shown in black, is highly compressed near the outer surface that is subject to aerothermal heating conditions. If surface recession occurs, the grid is compressed along the rays of the grid that intersect the heated surface. If pyrolysis occurs, the internal gas flow is assumed to be one-dimensional and quasi-steady along these rays. In the interior block, which is shaded yellow, the material may pyrolyze; however, there is no unique connection between the yellow rectangular cells and any specific ray of the external grid. Consequently, a TITAN calculation can retain its time accuracy only as long as ablation and the pyrolysis remain within the outer grid. This limitation prevents full application of TITAN to arcjet cases with large heat load or long exposure times such as conditions 2ab, 10b, 13, 15, 16, and 18-22 in Tables 2 and 3.

In order to present representative results across the range of conditions, seven primary cases corresponding to environment conditions $1,4 \mathrm{~b}, 6 \mathrm{a}, 8,12,14$, and 17 were selected for detailed analysis and presentation in this work. These seven conditions are listed in Table 5 and marked as numbered blue circles around black dots in Figure 8. For each successive condition, the nominal heat flux increases by a factor of $35 \%$ to $60 \%$.

In-depth thermal response along the centerline was calculated by FIAT results for all cases. The recession predictions from FIAT and TITAN at the axis agree to 2+ digits, because for PICA the ablation is insensitive to details of the in-depth conduction. The in-depth temperature response computed by FIAT becomes inaccurate with increasing time or depth; however, the results have some accuracy near the surface during the arcjet exposure period. FIAT in-depth temperature predictions will be presented for environment 21 where a TITAN calculation was not feasible. 


\section{Model Validation}

The PICAv3.3 material model is used by the analysis codes FIAT and TITAN to predict the surface temperature and recession as well as the in-depth conduction and decomposition of the material in response to aerothermal heating. Extensive arcjet testing provided a huge amount of data that may be compared with model predictions. In this section, we consider sequentially the surface recession, the surface temperature, the in-depth temperatures, and the post-test char profile. For each item we discuss the seven primary analysis cases from Table 5 and optionally selected notable results for other environments.

\section{A. Ablation Model}

Except for the most severe test conditions considered in this work, the ablation rate of PICA is dominated by the oxidation of carbon, which is highly sensitive to the oxygen concentration in the flow. Therefore the equilibrium ablation tables were generated for ten different argon-air mixtures applicable to the various ARC test conditions and for four different oxygen-to-nitrogen ratios applicable to the JSC test conditions. Predicted total recession for varying argon and six ARC test conditions is presented in Figures 11a and 11b. As the argon fraction is increased, the oxygen fraction is decreased, and as expected the total recession also decreases. The magnitude of this decrease is greatest at higher heat fluxes (Figure 11a), but the fractional decrease is greatest at the lowest heat flux (Figure $11 b)$.

We begin with comparisons of data and predictions for the seven cases in Table 5 that span the range of heat flux in the ARC arcjet tests. For each case, FIAT calculations were performed using the nominal aerothermal environment, and also with a $\pm 10 \%$ scaling factor applied to the heating. This factor is considered to be the minimum uncertainty of the arcjet environment. The predicted recession histories for the three heating levels for each case are presented in Figures 12a to $12 \mathrm{~g}$, in order of increasing heat flux. In all recession plots, the green, blue, and red curves are the FIAT predictions for $90 \%, 100 \%$, and $110 \%$ of nominal heating, respectively, and the black circles are measured data points from Table 4 with uncertainty bars of $\pm 0.5 \mathrm{~mm}$. The range of recession that results from the environmental uncertainty is shaded yellow. If the data points fall within the yellow-shaded region, then the ablation model cannot logically be assigned an error.

Case 1 at $107 \mathrm{~W} / \mathrm{cm}^{2}$ in Figure 12a has the largest disagreement, with FIAT underpredicting the data points. The measured recession was about $2.3 \mathrm{~mm}$ whereas FIAT predicts 1.5 to $2.1 \mathrm{~mm}$. The FIAT curves are concave upward for the entire 55-second exposure, because the PICA material does not reach a condition of steady-state ablation very quickly at low heat fluxes. For case 2 at $169 \mathrm{~W} / \mathrm{cm}^{2}$ (Figure 12b) FIAT underpredicts the data points, perhaps by a lesser extent than in case 1, and the curves have less upward curvature. For cases 3 to 5 , all the data points fall within the range of the predictions. The curves become quite linear for heat flux above $300 \mathrm{~W} / \mathrm{cm}^{2}$, because at high heat fluxes PICA quickly reaches a steady state of ablation. Case 6 at $744 \mathrm{~W} / \mathrm{cm}^{2}$ (Figure 12f) is an exception, where the data point falls below the range of FIAT predictions. Only one sample was tested, and it is possible that this sample experienced a lower heat flux than the calorimeter. Case 7 at $1102 \mathrm{~W} / \mathrm{cm}^{2}$ (Figure $12 \mathrm{~g}$ ) is the most severe environment, and the single data point lies in the center of the range of recession predicted by FIAT. For this environment, the material is primarily subliming rather than oxidizing.

For the dual-pulse test, condition 18, the models were exposed to two different heating environments. Figure 13 shows a very good agreement between the predictions and the data. Unfortunately, the recession was not measured after the first heat pulse.

Results for condition 5 are ambiguous. If the add air is assumed to mix perfectly with the main air flow, then the argon fraction at the centerline is $8 \%$, and FIAT overpredicts the recession for two of four samples (Figure 14a). Alternatively, if the add air is assumed not to mix with the main air flow, then the argon fraction is $26 \%$ at the centerline, and FIAT underpredicts the recession for one sample at 30-second exposure (Figure 14b). These results are consistent with the effect of argon discussed previously (cf. Figure 11). Similarly ambiguous results were calculated for AHF high add-air conditions 3 and 7. This effect was found to be not as significant for IHF conditions 9,15 , and 16. Unfortunately, because there is no direct measurement of the gas composition near the axis of the flow, it is not possible to eliminate this additional environmental uncertainty at this time.

Compared with the ARC facilities, the enthalpy profile in the JSC arcjet is more peaked near the axis. Consequently, the iso-q models tend to flatten in the center as they ablate. Also the stagnation conditions vary more significantly along the centerline as the model recedes away from the arcjet nozzle exit plane. Both effects tend to decrease the stagnation heat flux as a function of time. For these reasons, it was necessary to perform additional DPLR flowfield calculations. For test conditions 19 to 22, DPLR solutions were obtained for both the unablated and 
an ablated shape (approximated by an ellipsoid) at two different axial locations that spanned the maximum total recession obtained in the JSC tests. The DPLR environments were interpolated by FIAT to take into account the decrease in heat flux owing to recession and to shape change.

The FIAT results are compared with data for conditions 19 to 22, in Figures 15a to 15d, respectively. Each condition used different ablation tables that were generated for the appropriate oxygen fraction that varied from zero to $30 \%$. For three cases, the data are within the range predicted by FIAT, and for $10 \%$ oxygen, the data point is at the upper limit of the predicted range. For all four conditions the recession curves are concave downward, which is the opposite of the usual trend, because these calculations take into account the decrease in heat flux with time as discussed above.

The preceding discussion compared predictions of total recession with data from the arcjet models, where we assumed a minimal environmental uncertainty of $\pm 10 \%$. If the recession measurement is inside the range of predictions, then the recession prediction error is defined as zero. If the measurement is outside the range of predictions, then the error may be defined as

$$
E=\frac{\left(\Delta S_{\text {measured }}-\Delta S_{F I A T}\right)}{\left(\Delta S_{\text {measured }}\right)}
$$

where the closest FIAT result is used in the formula. This error is positive if the calculation under-predicts the data and negative if FIAT over-predicts the recession. The recession prediction error was calculated for all samples using FIAT results for perfect mixing of the add air. The results are plotted as a function of stagnation heat flux and pressure in Figures 16a and 16b, respectively. On both plots there are 47 points with zero error and 22 points with non-zero error.

As a function of heat flux (Figure 16a), there is no obvious trend, except for apparent scatter below $200 \mathrm{~W} / \mathrm{cm}^{2}$. The error is bounded by the horizontal blue lines at $\pm 12.5 \%$, except for one point from condition $5 \mathrm{a}$ with low measured recession. This exceptional point is the high add-air case that was discussed previously (Figures 14ab). If the add air is not perfectly mixed, the error for this data point may be any value between zero and $-21 \%$. The other low data point, at $-12 \%$ error, occurs in the high add-air environment 3 .

As a function of pressure (Figure 16b), a trend in the recession error is observed. The underpredicted points are clustered at low pressure, and the largest errors are at conditions 1, 2, and 4 with pressure below $6 \mathrm{kPa}$. The recession is expected to fall below the predictions of an equilibrium ablation model at sufficiently low surface temperatures, usually corresponding to heat fluxes below $90 \mathrm{~W} / \mathrm{cm}^{2}$, owing to kinetic limitations to carbon oxidation. However, it is unusual for recession to exceed the predictions of an equilibrium model. For these very low-pressure cases, the DPLR flowfield shows that the boundary layer is frozen, yet the oxygen is almost fully dissociated. This phenomenon occurs because, in an arcjet flow, the oxygen is dissociated upstream of the shock, unlike in a flight environment, where dissociation occurs as the flow passes through the shock. In the arcjet at sufficiently low pressure, the oxygen recombination rate is too small for oxygen atoms to equilibrate within the boundary layer. We believe the measured recession exceeds the predictions of the equilibrium model owing to the excessively high concentration of atomic oxygen reaching the surface. Development of a kinetic ablation model that is applicable to these low-pressure arcjet environments is an area of ongoing research.

\section{B. Surface Temperature}

As mentioned in the preceding subsection, for all test environments, FIAT calculations were performed using the nominal aerothermal environment, and also with a $\pm 10 \%$ scaling factor applied to the heating. The predicted surface temperature histories are shown in Figures $17 \mathrm{a}$ to $17 \mathrm{~g}$, in order of increasing heat flux for the seven cases of Table 5. In all surface temperature plots, the green and red curves are the FIAT predictions for $90 \%$ and $110 \%$ of nominal heating, respectively, and the region between these curves is shaded yellow. The gray squares are surface temperatures derived from pyrometer temperatures. The blue symbols are the average of the pyrometer data with $\pm \mathbf{5 \%}$ error bars. In many tests, useful data were obtained from three different pyrometers.

For the first five cases between 107 and $552 \mathrm{~W} / \mathrm{cm}^{2}$, in Figures 17a to 17e, the average pyrometer reading falls within the range predicted by FIAT. The amount of scatter of the pyrometer data varies on a run-to-run basis, but is less than the assumed uncertainty of $\pm 5 \%$. For case 6 at $744 \mathrm{~W} / \mathrm{cm}^{2}$ (Figure 17f), only one sample was tested and one of the one-color pyrometers failed to provide usable data. The FIAT predictions lie above the data obtained from the other two pyrometers. The FIAT prediction at $90 \%$ heating is within $5 \%$ uncertainty of the average pyrometer reading. This result is consistent with the recession results reported previously (Figure 12f) that suggested that this 
particular sample (ID number AA-44-218-N) experienced a lower heat flux than measured by the calorimeter. For case 7 at $1102 \mathrm{~W} / \mathrm{cm}^{2}$ (Figure $17 \mathrm{~g}$ ), only one sample was tested, and only one pyrometer was aimed toward the stagnation model. The other pyrometers were pointed at different locations in order to observe a large wedge model that was tested in the same arcjet run. This one pyrometer may not have been properly focused at the stagnation point, because the data does not smoothly reach a plateau as seen in the all other cases. Nevertheless, the FIAT predictions lie within the uncertainty range of the maximum pyrometer temperature.

The maximum surface temperature from the pyrometer data for every sample is listed in the last column of Table 4. Two maxima were obtained for each sample tested in the dual-pulse test (environments 18ab). The results are compared in Figure 18 with the maximum FIAT temperatures calculated for each environment. The plot is not a continuous function, primarily because the exposure durations vary from run to run. The pyrometer data inexplicably appear to plateau near $3000 \mathrm{~K}$ for heat fluxes between 500 and $1000 \mathrm{~W} / \mathrm{cm}^{2}$, whereas the model predictions show an increasing trend in this range of heat flux. Except for two environments, the FIAT predictions are within the uncertainty of the data. These exceptions are environments 5 and 16 , where all pyrometers are significantly below the predictions. The former environment is the high add-air case mentioned previously. Unlike recession predictions (Figures 14a and 14b), the surface temperature is relatively insensitive to the degree of add air mixing, and therefore it is unclear why add air should have any effect on pyrometer measurements. For the latter environment, the test models had a smaller diameter, and it is possible that the pyrometer data are not as accurate in this particular case.

\section{Thermal Response}

Initial calculations of the in-depth thermal response were performed using the FIAT code. For all test conditions, comparisons with data showed good agreement with thermocouple data only for relatively small times and depths. This discrepancy was attributed to multidimensional conduction effects. This hypothesis was confirmed by performing axisymmetric analysis with the TITAN code, using aerothermal boundary conditions generated by the DPLR code. Calculations were performed using $90 \%, 100 \%$, and $110 \%$ scaling of the nominal aerothermal environments. However, it is difficult to present results for multiple thermocouple locations and multiple environmental scalings on the same plot. Therefore, results will be presented only for the nominal environment, that is, $100 \%$ heating, unless otherwise noted.

Two samples were tested at condition 1. Figure 19a shows data and predictions for near-surface thermocouples TC1 to TC3 up to 160 seconds, and Figure 19b presents the data and predictions for TC3 to TC5 on a longer time scale. In these figures, the thermocouple data from the two samples are red and blue lines, the TITAN predictions are black lines, and FIAT predictions are green lines. TITAN provides a good match to both the magnitude and the time scale of the thermal response at all five locations, including the cool-down period up to 500 seconds. Although the time scale looks correct in the FIAT calculation, the magnitude of the predicted response is too low, especially for deep TC5. Clearly the one-dimensional calculation underpredicts the amount of thermal energy within the sample. The reason for this disagreement is fairly obvious; during arcjet exposure the model is heated along the whole exterior surface. The model sides have a larger surface area than the front face, and as shown previously, the heat flux is significant along the sides. Therefore there is a substantial heat load on the sides that increases the indepth temperatures above the level predicted by a one-dimensional analysis. Thermal penetration in the radial direction is enhanced by the relatively high in-plane thermal conductivity of PICA.

The measured in-depth temperatures from this and from all other PICA tests are characterized by a small temperature increase to approximately $330 \mathrm{~K}$ followed by a plateau or decrease until the conduction heat pulse reaches the depth of the thermocouple. In most cases, a small blip may be discerned in the data from TC3 and TC4, whereas an obvious hump is present in the data from TC5. This phenomenon has been observed in previous PICA testing $^{8}$ and is believed to be a small exothermic reaction within the phenolic phase. This phenomenon apparently is not related to oxidation, because it is seen when the material is tested in pure nitrogen. Modeling of this reaction is outside the scope of the current work.

At condition $4 \mathrm{~b}$ at $169 \mathrm{~W} / \mathrm{cm}^{2}$, PICA samples with both axial and radial thermocouples were tested. For this condition, the data are plotted with a different color for each thermocouple. Axial thermocouples TC1 to TC4 are shown in Figure 20a, and thermocouples at two different depths are given in Figures 20b and 20c. The near-surface thermocouple TCl failed near $2000 \mathrm{~K}$. For all ten thermocouple locations, the TITAN simulation provides an excellent match to the data. The agreement is particularly impressive during the cool-down period out to 700 seconds in Figure 20c. The small temperature hump at short time is visible in the data from TC4 and TC5. 
A similarly excellent agreement between data and predictions was obtained for case 3 (condition 6a) at 246 W/ $\mathrm{cm}^{2}$. Axial thermocouples TC1 to TC4 are shown in Figure 21a, and thermocouples at two different depths are given in Figures 21b and 21c. The agreement is impressive during the cool-down period out to 700 seconds in Figure 21c.

For cases 4 to 7, the data are plotted in the same manner as in case 1 . Results for case 4 at $395 \mathrm{~W} / \mathrm{cm}^{2}$ and case 5 at $552 \mathrm{~W} / \mathrm{cm}^{2}$ are presented in Figures 22ab and Figures 23ab, respectively. TITAN provides a reasonable match to all TCs, whereas the FIAT predictions for the deeper TCs fall increasingly below the data as the heat flux is increased.

For case 6 at $744 \mathrm{~W} / \mathrm{cm}^{2}$ the TITAN results for $100 \%$ heating overpredicted the temperature response at TC1 and TC2. However, both the surface recession and the surface temperature results suggest that this model experienced a lower heat flux than the calorimeter measurement. Therefore TITAN was re-run using $90 \%$ scaling of the aerothermal heat flux. The computed temperatures using $90 \%$ scaling agree well with the thermocouple measurements as shown in Figures 24ab.

Results for the highest heat flux case at $1102 \mathrm{~W} / \mathrm{cm}^{2}$ for 10 seconds are presented in Figures 25ab. TITAN provides a reasonable match for TCs 1 to 3 up to about 80 seconds. Between 75 and 115 seconds, a large wedge model was tested. This time interval is indicated by the yellow shading on Figure 25a. The stagnation model, although not directly in the arcjet flowfield, clearly experienced additional heating during this time, as indicated by the unusual plateau in the TC1 data. This additional heating may be a result of both flow deflection and radiation from the wedge model. As a consequence of the additional heat load, the data from the deeper TCs rise above the TITAN predictions during the cool-down period after 100 seconds.

As a final example of the conduction model, Figure 26 presents FIAT predictions and thermocouple data for condition 21 . One sample was tested at JSC in simulated air with $23 \%$ oxygen. The exposure duration of 120 seconds was excessive for this model design; consequently, almost $60 \%$ of the model ablated, including the four thermocouples closest to the surface. The type-R and type-K thermocouples appear to fail near $2000 \mathrm{~K}$ and $1650 \mathrm{~K}$, respectively. Only the deepest thermocouple survived the arcjet exposure. FIAT calculations were performed using the nominal aerothermal environment, and also with a $\pm 10 \%$ scaling factor applied to the heating. The data fall within the range of the predictions up to 160 seconds, after which time FIAT underpredicts the data for TC5.

In the past, the in-depth thermal response of PICA in arcjet models was difficult to model accurately using onedimensional analysis tools. The calculations presented herein clearly demonstrate that the one-dimensional analyses are inadequate because the thermal response is strongly affected by multidimensional conduction. The new PICAv3.3 thermal and ablation model, which takes into account orthotropic material properties, combined with multidimensional thermal analysis and CFD-based boundary conditions, provides a good agreement with in-depth temperature data across the entire range of stagnation test conditions considered in this work.

\section{Ablated Shape and Char Depth}

For each of the seven primary analysis cases, one post-test sample was cross sectioned and photographed. From the TITAN solutions, the ablated shape and in-depth density contours at the final time ( 700 seconds) were plotted. These photographs and plots are compared in Figures $27 \mathrm{a}$ to $27 \mathrm{~g}$ for the seven cases, in order of increasing heat flux. The TITAN results are shown on the left side of each figure. Nine density contours corresponding to $10 \%$ to $90 \%$ charred material are drawn on each TITAN plot. The $10 \%$ contour, which corresponds to near-virgin material, has the greatest in-depth penetration. The $90 \%$ contour, which corresponds to highly charred material, has the least indepth penetration. The eight density contours, for $20 \%$ to $90 \%$ charred material, tend to cluster and thereby provide an indication of the thickness of the pyrolysis zone. For all seven cases the clustered TITAN contours match the visual location of the pyrolysis zone both on the axis and at the sidewall.

The post-test char depth shows the thermal penetration minus the amount of material ablated. The former increases with exposure duration, whereas the latter increases with heat flux. Except for cases 1 and 2, in these tests the exposure duration was decreased as the heat flux was increased. The net result of these conflicting trends is that the post-test char depth decreases with increasing heat flux. The char is thinnest in Case 7 at $1102 \mathrm{~W} / \mathrm{cm}^{2}$, because the exposure duration was only 10 seconds.

\section{Conclusions and Recommendations}

Data were presented from stagnation arcjet tests conducted on iso-q shaped PICA models. These models were tested in the AHF and IHF facilities at NASA ARC and in the TP2 facility at NASA JSC at twenty-two test 
conditions spanning stagnation-point heat fluxes of approximately 100 to $1100 \mathrm{~W} / \mathrm{cm}^{2}$ and including different gas compositions. In-depth temperatures were measured at five to ten different locations including both axial and offaxis thermocouples. For most samples, the surface temperature was measured using three different pyrometers. Posttest recession was measured by two methods, and selected models were cross-sectioned to reveal the char depth.

A new ablation and thermal-response model, that includes orthotropic and pressure-dependent thermal conductivity, was developed based on extensive thermal, mechanical, and general property testing of newly manufactured PICA. One-dimensional FIAT and two-dimensional TITAN simulations of the ablation and thermal response of PICA were performed for the entire set of arcjet test conditions, using as boundary conditions the aerothermal environments predicted by the DPLR code. The simulations took into account the variations in gas composition and an estimated uncertainty of $\pm 10 \%$ for heat flux. The DPLR-based environments were found to be more reliable than values such as centerline enthalpy that often are estimated by correlations.

The effect of gas composition, in particular dilution of oxygen by argon or nitrogen, is significant in prediction of recession of a carbonaceous ablator such as PICA. In this work, the argon mass fraction varied from $0 \%$ to $27 \%$, depending on the facility and the test conditions. In order to obtain accurate recession predictions, it was necessary to generate many sets of ablation tables, with each set applicable only to a narrow range of gas compositions, so that for every analysis case, the appropriate set of tables could be selected.

With the exception of one sample, recession predictions using ablation tables for the applicable gas composition were within $\pm 12.5 \%$ of measured values, after the nominal environmental uncertainty was taken into account. The use of add air changes the oxygen fraction by an unknown amount, depending on the degree of add air mixing into the core of the flow. The uncertainty of gas composition was an additional complication for interpretation of results at three AHF test conditions, including the one sample mentioned above.

Comparisons of in-depth predictions with data show that one-dimensional modeling is inadequate, because the thermal response is strongly influenced by multidimensional heat conduction. Using the multidimensional and orthotropic thermal conductivity model with CFD-based boundary conditions, the in-depth thermal response was well predicted in all cases.

Thermal penetration as indicated by char depth in cross sections also was qualitatively predicted. For 17 of the 19 exposure environments with pyrometer data, surface temperature predictions were within $\pm 5 \%$ uncertainty of the average pyrometer measurement.

In future tests, if a quantitative recession measurement is desired, test durations sufficient to achieve at least 5 and preferably 8 to $10 \mathrm{~mm}$ of recession are recommended. Such test durations may be excessive for validation of thermal response models. In this case, multiple exposure durations should be used to provide useful data for both purposes.

The use of both argon and air significantly complicates the modeling and analysis process. Different ablation tables are required, depending on the arcjet argon fraction, and these arcjet tables are different from the tables used for flight analyses. Furthermore, if add air is used, then the amount of argon at any location in the flowfield is indeterminate and depends on the degree of gas mixing. We recommend to eliminate the use of argon. If nitrogen is used to shield the upstream electrode, then a calibrated amount of oxygen may be added in the front portion of the arcjet to achieve the correct ratio of nitrogen to oxygen for air. This recommended process would eliminate both the need for multiple sets of ablation tables and the ambiguity of element fractions caused by the use of add air.

\section{Acknowledgments}

The authors greatly appreciate the assistance of P. Agrawal, M. Olson, and especially K. Skokova for arcjet test data, and T. Gokcen and D. Prabhu for DPLR analyses of arcjet flowfields. This work was supported by the Orion TPS Advanced Development Project.

\section{References}

\footnotetext{
${ }^{1}$ Tran, H., Johnson, C, Rasky, D., Hui, F., Chen, Y.-K., and Hsu, M., "Phenolic Impregnated Carbon Ablators (PICA) for Discovery Class Missions," AIAA Paper 96-1911, June 1996.

${ }^{2}$ Willcockson, W.H,. "Stardust Sample Retum Capsule Design Experience," Journal of Spacecraft and Rockets, Vol. 36, No. 3, 1999, pp. 470-474.

${ }^{3}$ Milos, F.S., and Chen, Y.-K., "Ablation and Thermal Property Model for Phenolic Impregnated Carbon Ablator (PICA)," NASA-TM-TBD, Dec. 2008. [The TM number should be available this month!!]

${ }^{4}$ Chen, Y.-K., and Milos, F.S., “Ablation and Thermal Analysis Program for Spacecraft Heatshield Analysis," Journal of Spacecraft and Rockets, Vol. 36, No. 3, 1999, pp. 475-483.
} 
${ }^{5}$ Chen, Y.-K., and Milos, F.S., "Two-Dimensional Implicit Thermal Response and Ablation Program for Charring Materials," Journal of Spacecraft and Rockets, Vol. 38, No. 4, 2001, pp. 473-481.

${ }^{6}$ Milos, F.S., and Chen, Y.-K., "Two-Dimensional Ablation, Thermal Response, and Sizing Program for Pyrolyzing Ablators," AIAA Paper 2008-1223, Jan. 2008.

${ }^{7}$ Milos, F.S. and Chen, Y.-K., "Comprehensive Model for Multicomponent Ablation Thermochemistry," AIAA Paper 970141, Jan. 1997

${ }^{8}$ Covington M.A, Heinemann, J.M., Goldstein, H.E., Chen, Y.-K., Terrazas-Salinas, I., Balboni, J.A., Olejniczak, J., and Martinez, E.R., "Performance of a Low Density Ablative Heat Shield Material," Journal of Spacecraft and Rockets, Vol. 45, No. 2, 2008, pp. 237-247.

${ }^{9}$ Wright, M.J., Candler, G.V., and Bose, D., "Data-Parallel Line Relaxation Method for the Navier-Stokes Equations," $A I A A$ Journal, Vol. 36, No. 9, 1998, pp 1603-1609.

${ }^{10}$ Anon., "Standard Test Method for Measuring Heat-Transfer Rate Using a Thermal Capacitance (Slug) Calorimeter," ASTM Standard E-457-08.

${ }^{11}$ Balter-Peterson, A., Nichols, F., Mifsud, B., and Love, W., "Arc Jet Testing in NASA Ames Research Center Thermophysics Facilities," AIAA Paper 1992-5041, Dec. 1992.

${ }^{12}$ Winovich, W., and Carlson, W., "The 60-MW Shuttle Interaction Heating Facility," Proceedings of the 25th International Instrumentation Symposium, Instrument Society of America, Pittsburgh, PA, 1979, pp. 59-75.

${ }^{13}$ Anon., "Standard Practice for Internal Temperature Measurements in Low-Conductivity Materials," ASTM Standard E377-96.

${ }^{14}$ Zoby, E. V., "Empirical Stagnation-Point Heat-Transfer Relation in Several Gas Mixtures at High Enthalpy Levels," NASA TN D-4799, Oct. 1968.

${ }^{15}$ Stackpoole, S., Sepka, S, and Ioana Cozmuta, I., "Post-Flight Evaluation of Stardust Sample Return Capsule Forebody Heatshield Material," AIAA Paper 2008-1202, Jan. 2008.

${ }^{16}$ Chen, Y.-K., Milos, F.S., and Gökçen, T., "Loosely Coupled Simulation for Two-Dimensional Ablation and Shape Change," AIAA Paper 2008-3802, June 2008.

Table 1. Nominal thermocouple locations within arcjet models

\begin{tabular}{|c|c|c|c|c|c|}
\hline \multirow{2}{*}{$\begin{array}{c}\text { TC } \\
\text { number }\end{array}$} & \multirow{2}{*}{$\begin{array}{c}\text { Radial } \\
\text { Location } \\
\text { (cm) }\end{array}$} & \multicolumn{4}{|c|}{ Axial Depth (cm) for Four TC Placement Options } \\
\hline & & $\mathbf{A}$ & $\mathbf{B}$ & $\mathbf{C}$ & $\mathbf{D}$ \\
\hline 1 & 0.000 & 0.381 & 0.508 & 0.635 & \\
\hline 2 & 0.000 & 0.762 & 0.889 & 1.016 & \\
\hline 3 & 0.000 & 1.143 & 1.270 & 1.397 & \\
\hline 4 & 0.000 & 1.524 & 1.651 & 1.778 & \\
\hline 5 & 0.000 & 3.048 & 3.048 & 3.048 & 3.048 \\
\hline 6 & 0.000 & & & & 2.286 \\
\hline 7 & 2.540 & & & & 2.286 \\
\hline 8 & 3.810 & & & & 2.286 \\
\hline 9 & 4.445 & & & & 2.286 \\
\hline 10 & 4.445 & & & & 3.048 \\
\hline
\end{tabular}


Paper AIAA-2009-0262 for the 47th AIAA Aerospace Sciences Meeting, Orlando, Florida, 5-8 January 2009.

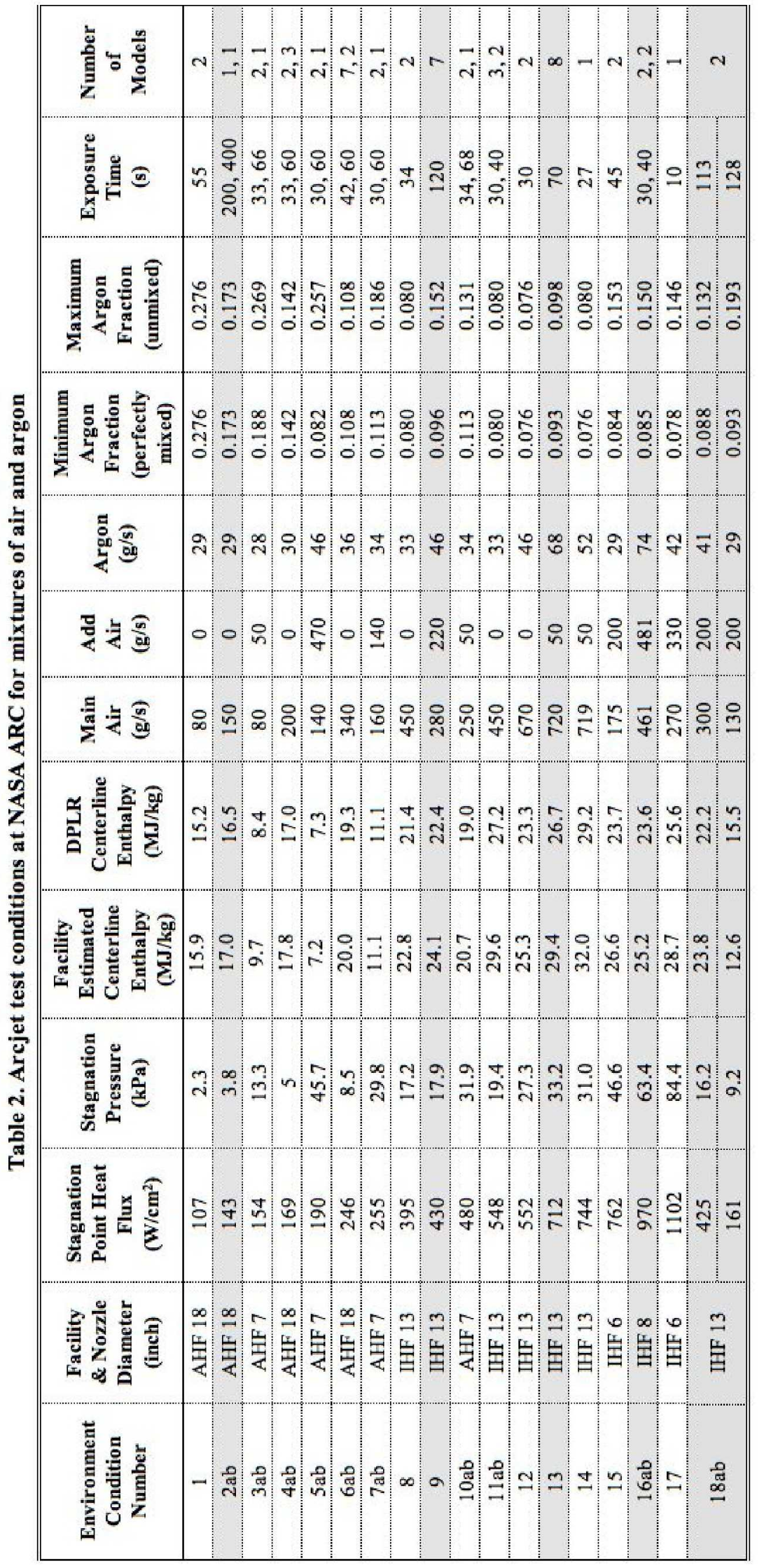

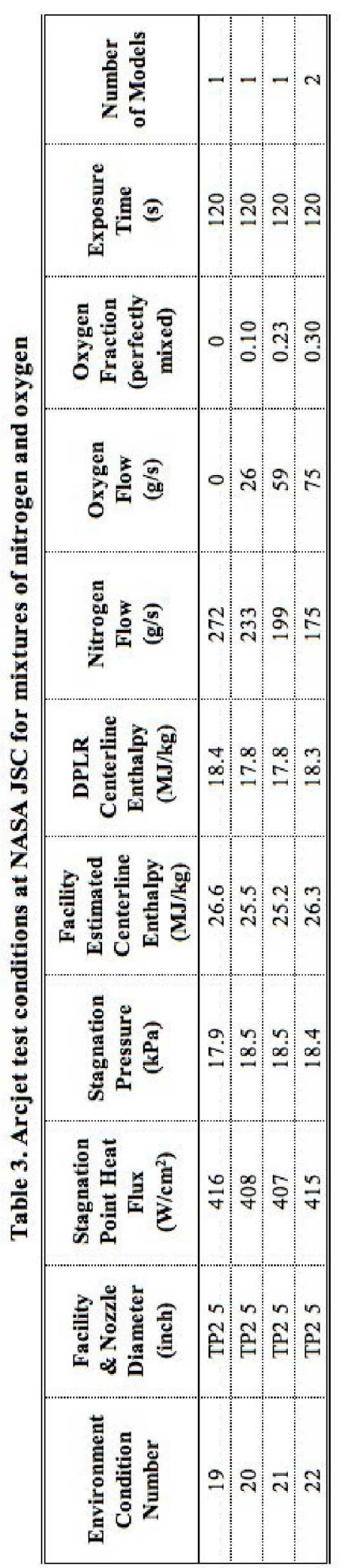


Table 4. Test conditions, thermocouple placement option, centerline recession, and maximum temperature for each arcjet model

\begin{tabular}{|c|c|c|c|c|c|}
\hline $\begin{array}{l}\text { Condition } \\
\text { Number }\end{array}$ & $\begin{array}{c}\text { Exposure } \\
\text { Time } \\
\text { (s) }\end{array}$ & Model ID & TC Option & $\begin{array}{c}\text { Centerline } \\
\text { Recession } \\
\text { (mm) }\end{array}$ & $\begin{array}{c}\text { Maximum } \\
\text { Surface } \\
\text { Temperature } \\
\text { (K) }\end{array}$ \\
\hline 1 & 55 & AA-43-209-N & A & 2.33 & 2033 \\
\hline 1 & 55 & AA-43-210-N & A & 2.27 & 2041 \\
\hline $2 a$ & 200 & AT-008 & none & 12.66 & 2177 \\
\hline $2 b$ & 400 & AT-007 & none & 24.72 & 2196 \\
\hline $3 a$ & 33 & AA-44-210-N & $\mathrm{B}$ & 2.93 & 2161 \\
\hline $3 a$ & 33 & AA-44-211-N & B & 2.92 & 2174 \\
\hline $3 b$ & 66 & AA-44-212-N & B & 5.61 & 2163 \\
\hline $4 a$ & 33 & AA-43-211-N & A & 2.27 & 2243 \\
\hline $4 a$ & 33 & AA-43-212-N & A & 2.20 & 2245 \\
\hline $4 b$ & 60 & AA-43-208-N & $\mathbf{A}$ & 4.28 & 2248 \\
\hline $4 b$ & 60 & 1403 & D & 4.58 & 2259 \\
\hline $4 b$ & 60 & 1404 & $\mathrm{D}$ & 4.76 & 2284 \\
\hline $5 a$ & 30 & AA-44-204-N & $\mathrm{B}$ & 4.78 & 1989 \\
\hline $5 a$ & 30 & AA-44-205-N & $\mathrm{B}$ & 3.79 & 2004 \\
\hline $5 b$ & 60 & AA-44-206-N & B & 8.81 & 2065 \\
\hline $6 a$ & 42 & AA-43-213-N & $\mathbf{A}$ & 3.71 & 2407 \\
\hline $6 a$ & 42 & AA-43-215-N & A & 3.65 & 2414 \\
\hline $6 a$ & 42 & AA-43-207-N & A & 3.95 & 2401 \\
\hline $6 a$ & 42 & AA-43-216-N & B & 3.52 & 2432 \\
\hline $6 a$ & 42 & AA-43-227-N & $\mathrm{B}$ & 3.68 & 2419 \\
\hline $6 a$ & 42 & 1405 & $\mathrm{D}$ & 4.12 & 2437 \\
\hline $6 a$ & 42 & 1406 & D & 3.69 & 2417 \\
\hline $6 b$ & 60 & AA-43-223-N & A & 5.21 & 2434 \\
\hline $6 b$ & 60 & AA-43-228-N & A & 5.23 & 2409 \\
\hline $7 \mathrm{a}$ & 30 & AA-44-201-N & B & 3.87 & 2331 \\
\hline $7 \mathrm{a}$ & 30 & AA-44-202-N & $\mathrm{B}$ & 4.33 & 2320 \\
\hline $7 \mathrm{~b}$ & 60 & AA-44-203-N & $\mathrm{B}$ & 8.52 & 2359 \\
\hline 8 & 34 & AA-43-219-N & $\mathrm{B}$ & 4.61 & 2730 \\
\hline 8 & 34 & AA-43-218-N & $\mathrm{B}$ & 4.43 & 2735 \\
\hline 9 & 120 & AT-011 & none & 16.45 & 2703 \\
\hline 9 & 120 & AT-019 & none & 18.66 & 2718 \\
\hline 9 & 120 & AT-025 & none & 19.06 & 2713 \\
\hline 9 & 120 & AT-026 & none & 19.03 & 2697 \\
\hline 9 & 120 & AA-40-001 & none & 17.71 & 2682 \\
\hline 9 & 120 & AA-40-002 & none & 17.64 & 2677 \\
\hline 9 & 120 & AA-40-003-N & none & 16.25 & 2662 \\
\hline $10 \mathrm{a}$ & 34 & AA-44-207-N & $\mathrm{B}$ & 6.32 & 2757 \\
\hline $10 \mathrm{a}$ & 34 & AA-44-208-N & $\mathrm{B}$ & 6.58 & 2764 \\
\hline $10 \mathrm{~b}$ & 68 & AA-44-209-N & $\mathrm{B}$ & 13.63 & 2738 \\
\hline $11 \mathrm{a}$ & 30 & AA-43-221-N & B & 4.18 & 2990 \\
\hline $11 \mathrm{a}$ & 30 & AA-43-224-N & B & 4.55 & 2923 \\
\hline $11 \mathrm{a}$ & 30 & AA-43-226-N & $\mathrm{B}$ & 4.30 & 2943 \\
\hline $11 \mathrm{~b}$ & 40 & AA-43-222-N & $\mathrm{B}$ & 5.89 & 2988 \\
\hline $11 b$ & 40 & AA-43-225-N & B & 5.92 & 2934 \\
\hline 12 & 30 & AA-43-233-N & $\mathrm{B}$ & 5.41 & 2963 \\
\hline
\end{tabular}


Paper AIAA-2009-0262 for the 47th AIAA Aerospace Sciences Meeting, Orlando, Florida, 5-8 January 2009.

\begin{tabular}{|c|c|c|c|c|c|}
\hline $\begin{array}{l}\text { Condition } \\
\text { Number }\end{array}$ & $\begin{array}{c}\text { Exposure } \\
\text { Time } \\
\text { (s) }\end{array}$ & Model ID & TC Option & $\begin{array}{l}\text { Centerline } \\
\text { Recession } \\
\text { (mm) }\end{array}$ & $\begin{array}{c}\text { Maximum } \\
\text { Surface } \\
\text { Temperature } \\
\text { (K) }\end{array}$ \\
\hline 12 & 30 & AA-43-234-N & B & 4.97 & 2963 \\
\hline 13 & 70 & AT-012 & none & 12.57 & 2984 \\
\hline 13 & 70 & AT- 020 & none & 14.56 & 3030 \\
\hline 13 & 70 & AT-027 & none & 15.00 & 3053 \\
\hline 13 & 70 & AT- 028 & none & 15.33 & 3015 \\
\hline 13 & 70 & AA- $40-003$ & none & 13.82 & 2994 \\
\hline 13 & 70 & AA-40-004 & none & 11.58 & 2994 \\
\hline 13 & 70 & AA-40-001-N & none & 13.79 & 2969 \\
\hline 13 & 70 & AA-40-002-N & none & 12.83 & 2984 \\
\hline 14 & 27 & AA-44-218-N & $\mathrm{C}$ & 5.13 & 3030 \\
\hline 15 & 45 & AA-44-223-N & $\mathbf{C}$ & 12.74 & 3098 \\
\hline 15 & 45 & AA-44-224-N & $\mathrm{C}$ & 12.91 & 3098 \\
\hline $16 a$ & 30 & AT-001 & none & 11.97 & 3020 \\
\hline $16 a$ & 30 & $\mathrm{AT}-004$ & none & 11.33 & 3051 \\
\hline $16 b$ & 40 & AT-003 & none & 15.15 & 3020 \\
\hline $16 b$ & 40 & AT-005 & none & 15.56 & 3030 \\
\hline 17 & 10 & AA-44-219-N & C & 4.84 & 3233 \\
\hline $18 \mathrm{a}$ & 113 & \multirow{2}{*}{ AT-009 } & \multirow{2}{*}{ none } & not measured & 2728 \\
\hline $18 b$ & 128 & & & 26.95 & 2218 \\
\hline $18 \mathrm{a}$ & 113 & \multirow{2}{*}{ AT-010 } & \multirow{2}{*}{ none } & not measured & 2738 \\
\hline $18 \mathrm{~b}$ & 128 & & & 27.05 & 2213 \\
\hline 19 & 120 & AA-44-214-N & $\mathrm{B}$ & 1.75 & not measured \\
\hline 20 & 120 & AA-44-216-N & $\mathrm{B}$ & 12.0 & not measured \\
\hline 21 & 120 & AA-44-213-N & $\mathrm{B}$ & 20.5 & not measured \\
\hline 22 & 120 & AA-44-215-N & $\mathrm{B}$ & 24.1 & not measured \\
\hline 22 & 120 & AA-44-229-N & $\mathrm{B}$ & 23.9 & not measured \\
\hline
\end{tabular}

Table 5. Seven cases selected for detailed analysis

\begin{tabular}{|c|c|c|c|c|}
\hline $\begin{array}{l}\text { Analysis } \\
\text { Case } \\
\text { Number }\end{array}$ & $\begin{array}{c}\text { Environment } \\
\text { Condition } \\
\text { Number }\end{array}$ & $\begin{array}{c}\text { Stagnation Point } \\
\text { Heat Flux } \\
\left(\mathrm{W} / \mathrm{cm}^{2}\right)\end{array}$ & $\begin{array}{c}\text { Stagnation } \\
\text { Pressure } \\
\text { (kPa) }\end{array}$ & $\begin{array}{c}\text { Exposure } \\
\text { Time } \\
\text { (s) }\end{array}$ \\
\hline 1 & 1 & 107 & 2.3 & 55 \\
\hline 2 & $4 b$ & 169 & 5.0 & 60 \\
\hline 3 & $6 a$ & 246 & 8.5 & 42 \\
\hline 4 & 8 & 395 & 17.2 & 34 \\
\hline 5 & 12 & 552 & 27.3 & 30 \\
\hline 6 & 14 & 744 & 31.0 & 27 \\
\hline 7 & 17 & 1102 & 84.4 & 10 \\
\hline
\end{tabular}




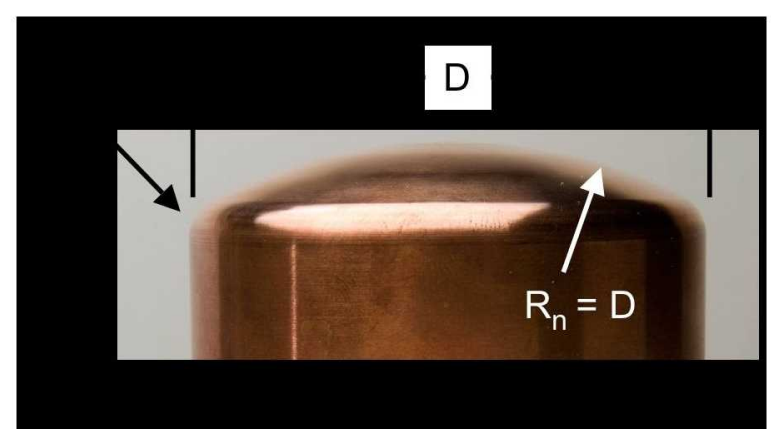

Figure 1. Model shape for stagnation arcjet tests. TPS samples have the same external shape as the calorimeter used to measure the heat flux and stagnation pressure.

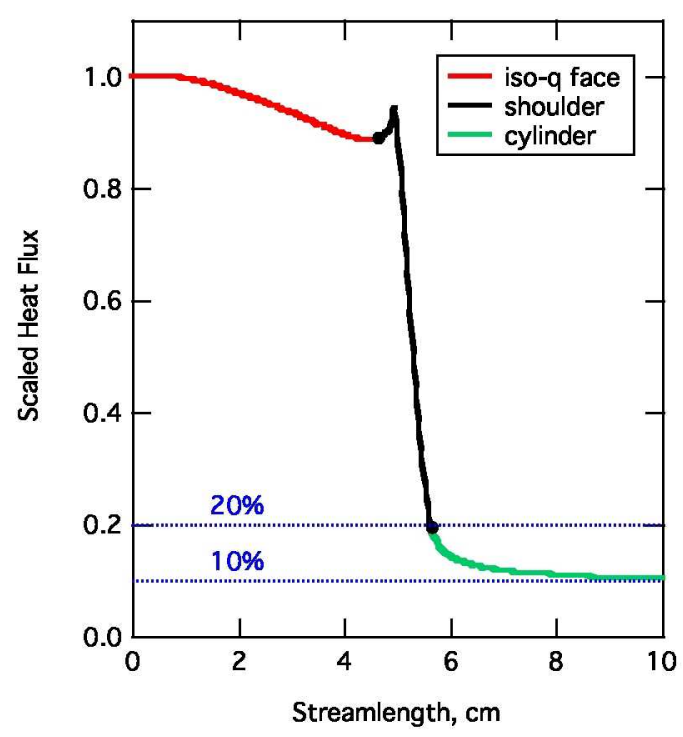

Figure 2. Normalized heat flux distribution for sample with iso-q shape.

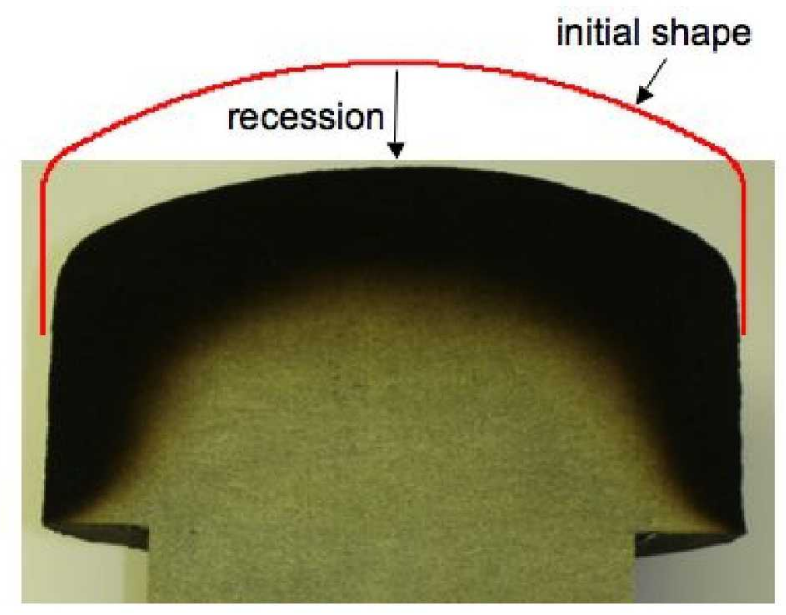

Figure 3. Cross section of iso-q model AT-008 tested for 200 seconds. The ablated shape, after $13 \mathrm{~mm}$ of recession, is comparable to the initial shape. 


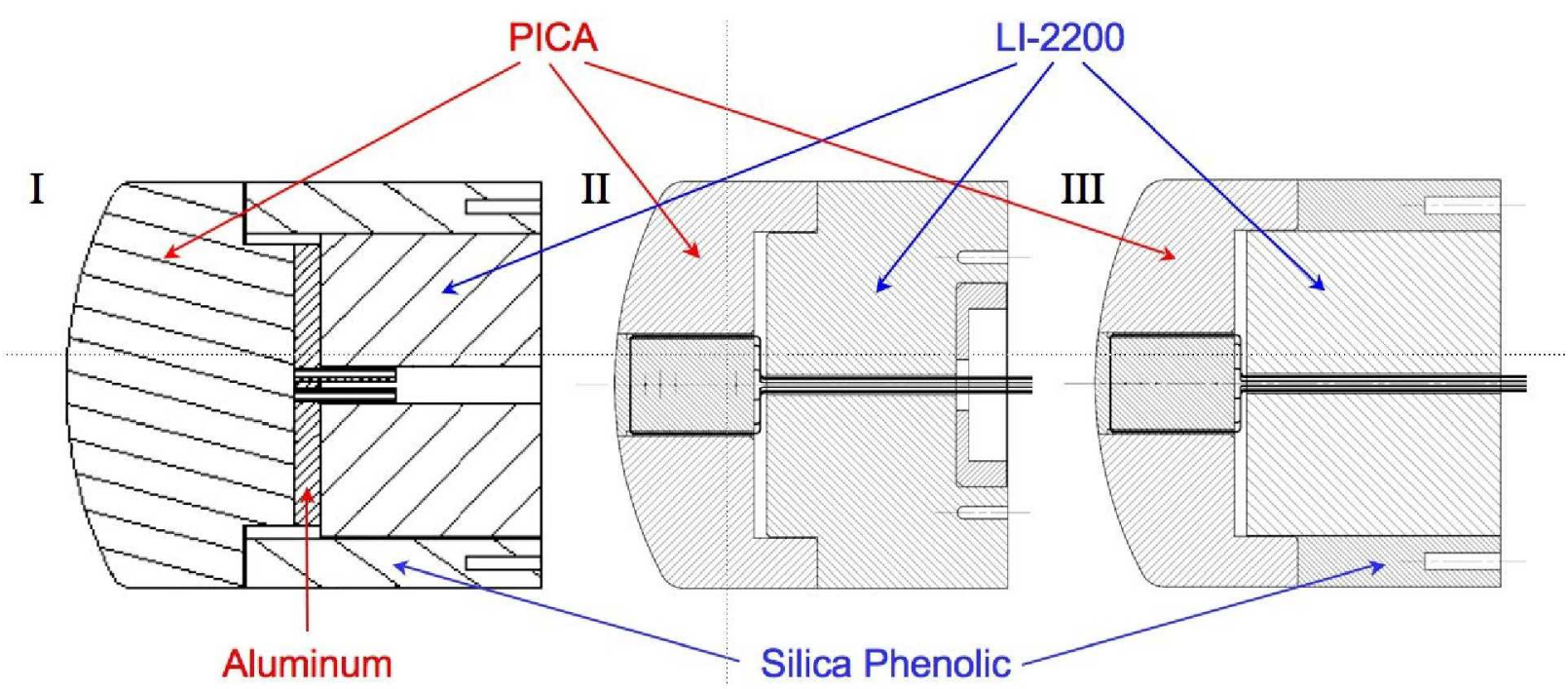

Figure 4. Cross section of iso-q arcjet models. Model type I is uninstrumented. Model types II and III may contain a thermocouple plug (as shown), and the initial thickness at the stagnation point varied from 3.49 to $4.13 \mathrm{~cm}$. A silicaphenolic collar is used in all tests with stagnation heat flux greater than $700 \mathrm{~W} / \mathrm{cm}^{2}$.
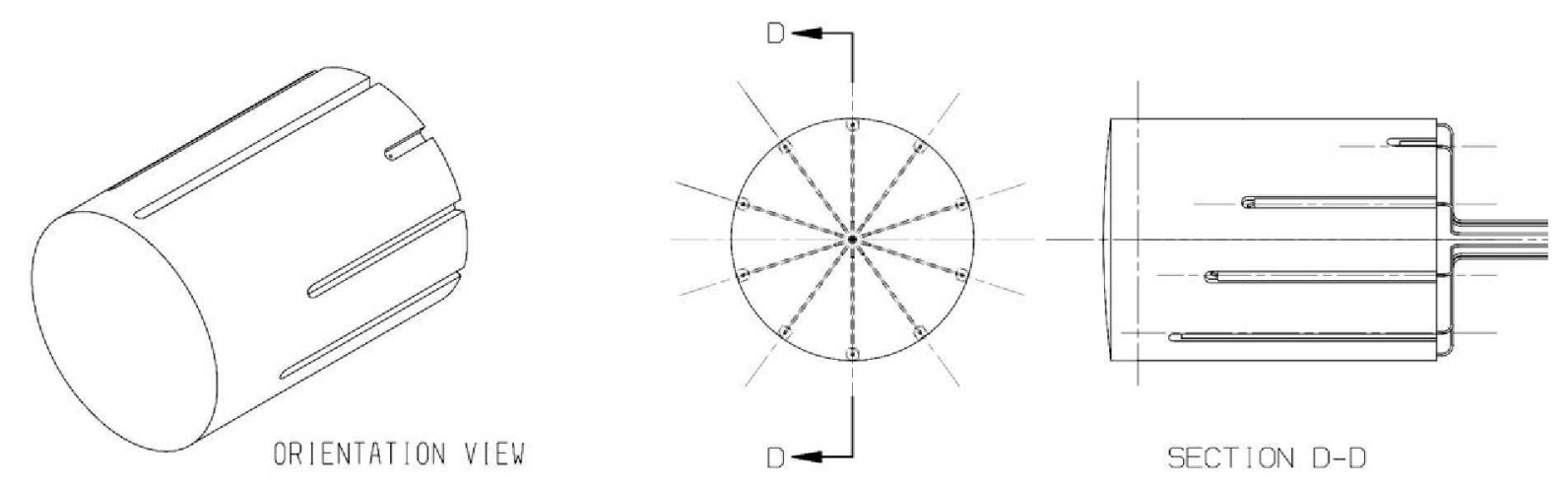

Figure 5. Axial plug containing thermocouples 1 to 5 for model types II and III.

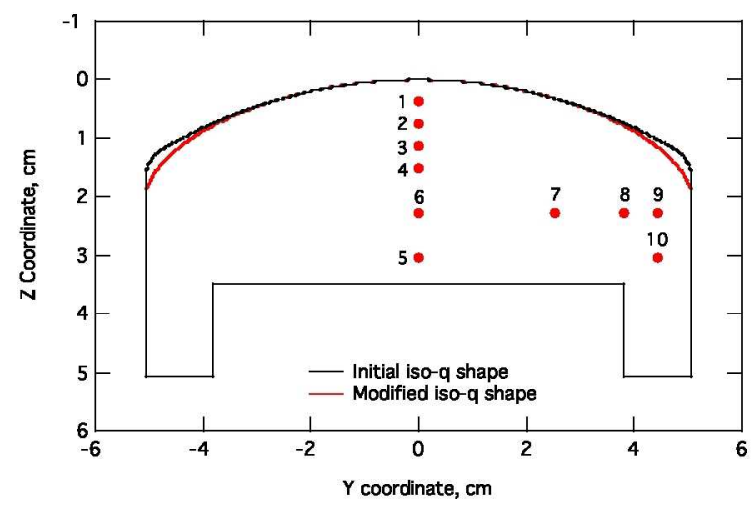

Figure 6. Cross-sectional drawing of iso-q shaped arcjet model with thermocouple locations for Types B and D. Thermocouples are not co-planar. 

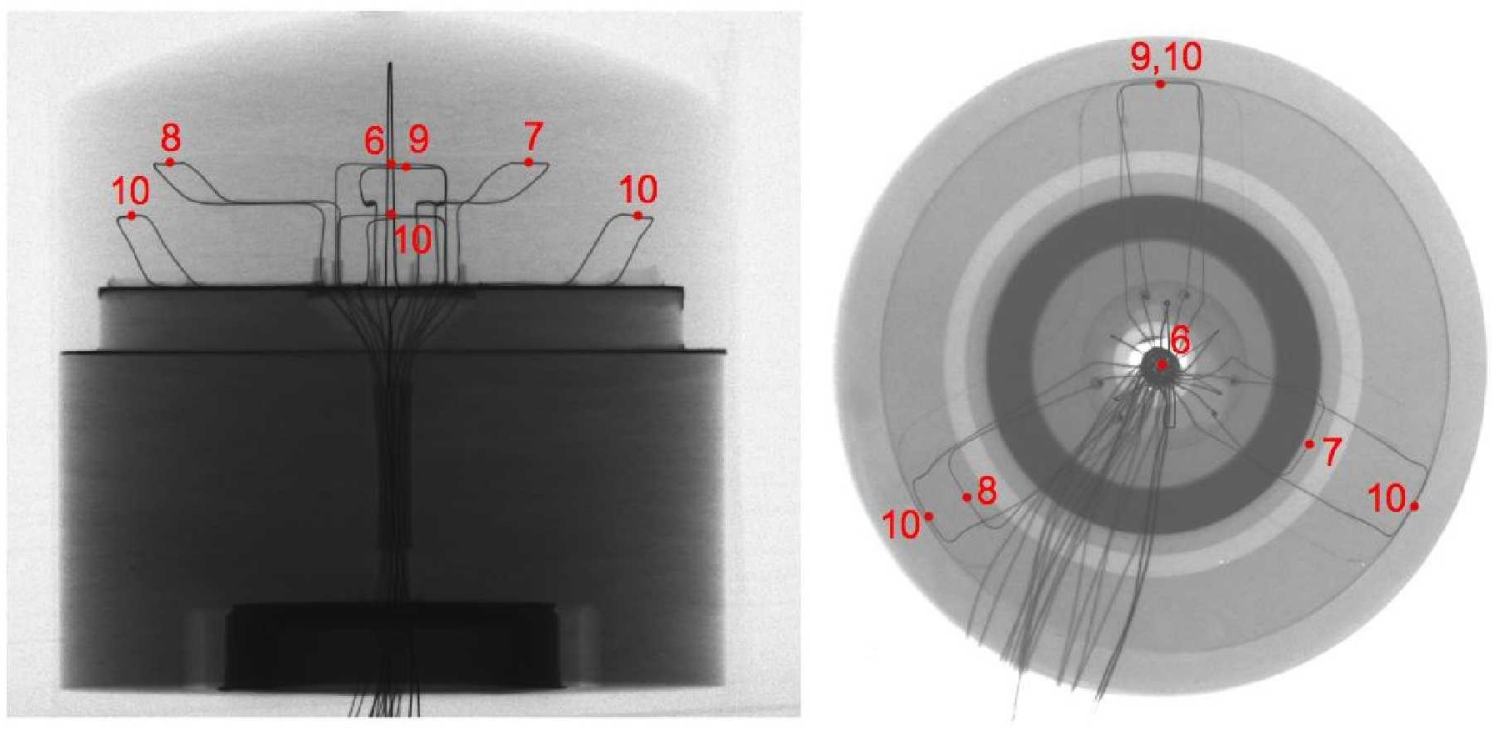

Figure 7. Side-view and top-view x-ray images of arcjet model with thermocouple placement $D$.

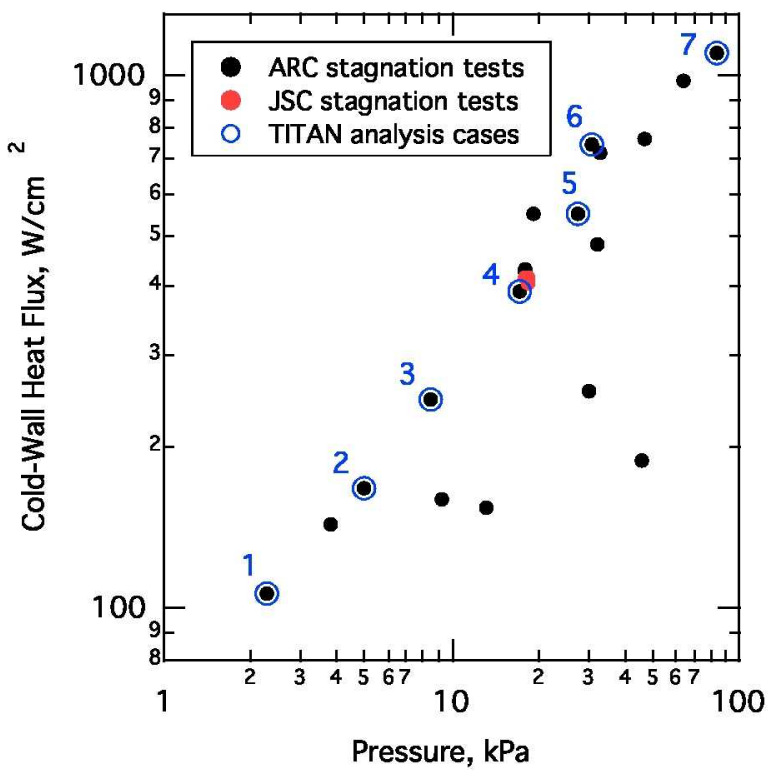

Figure 8. Measured stagnation pressure and cold-wall heat flux for test conditions in Tables 2 and 3. Circled dots indicate seven conditions to be discussed in detail. 

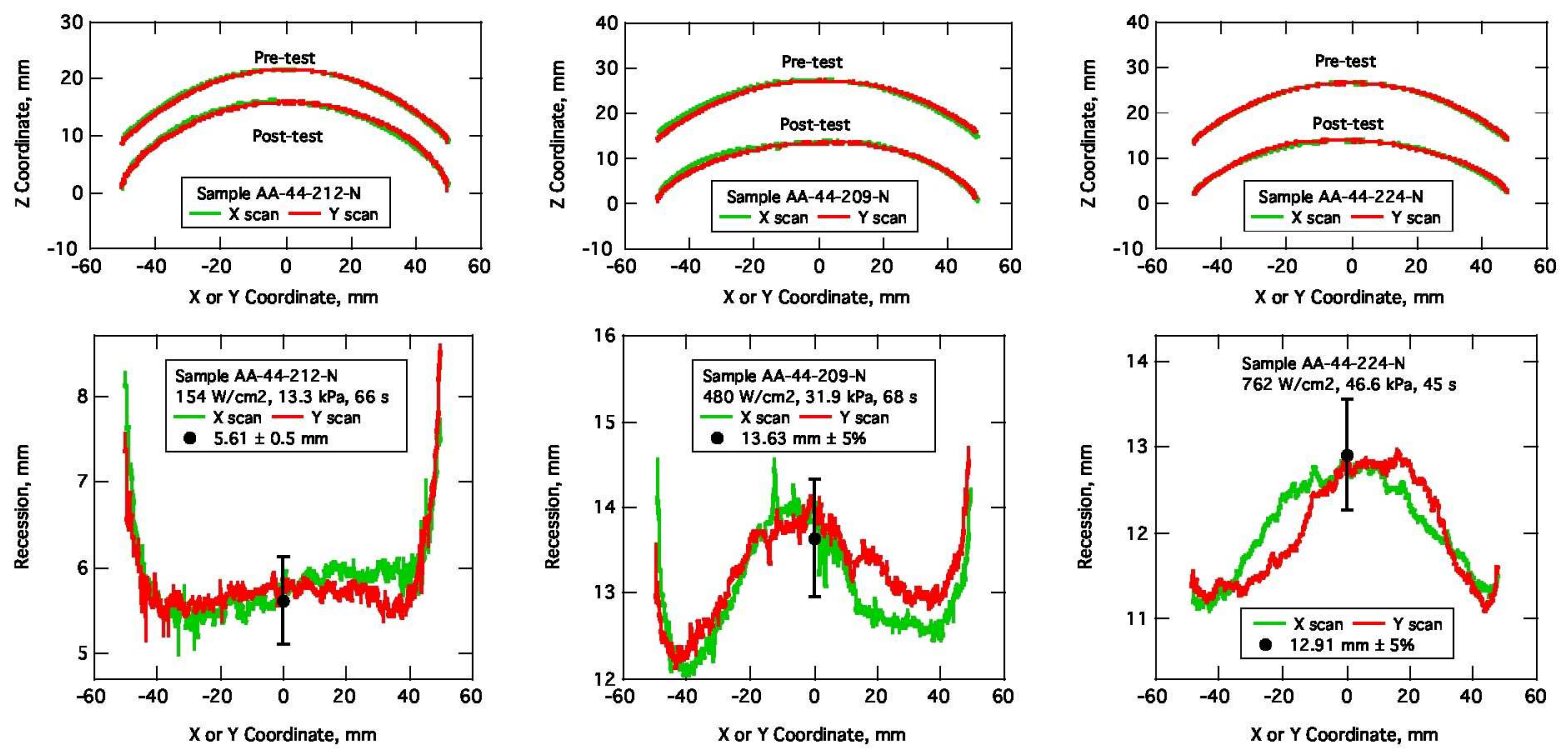

Figure 9. Three examples of recession calculated from laser scan profiles. The black dot is the manually-measured centerline value.

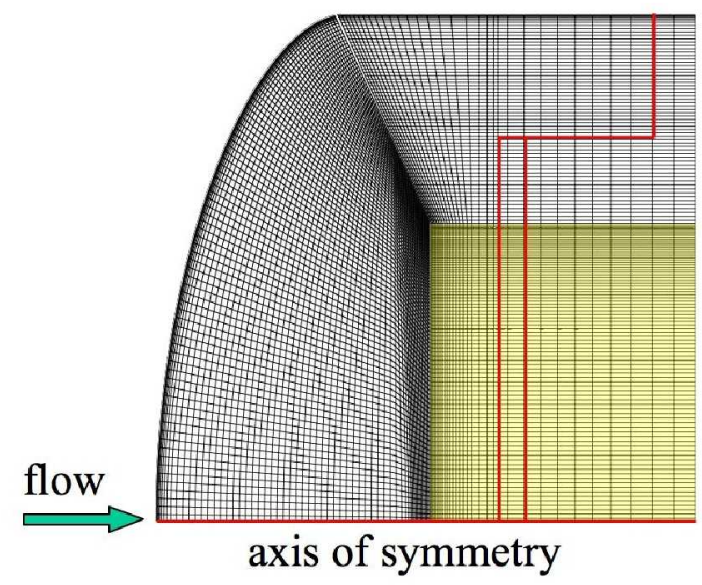

Figure 10. Front portion of two-block TITAN grid for arcjet model of Type II or III with modified iso-q shape. The interior block is shaded yellow. 
Paper AIAA-2009-0262 for the 47th AIAA Aerospace Sciences Meeting, Orlando, Florida, 5-8 January 2009.

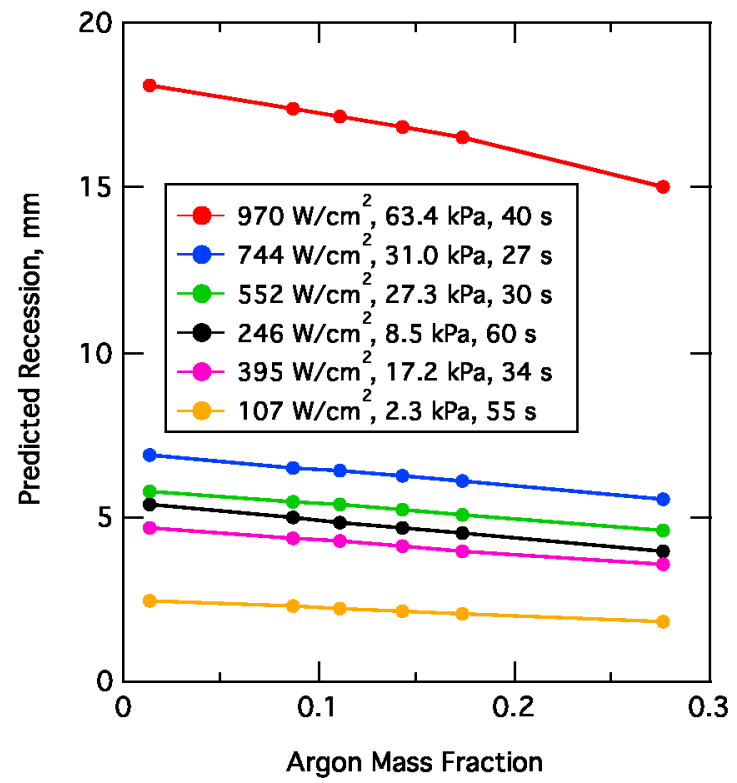

Figure 11 a. Effect of argon fraction on recession for nominal (100\%) heating.

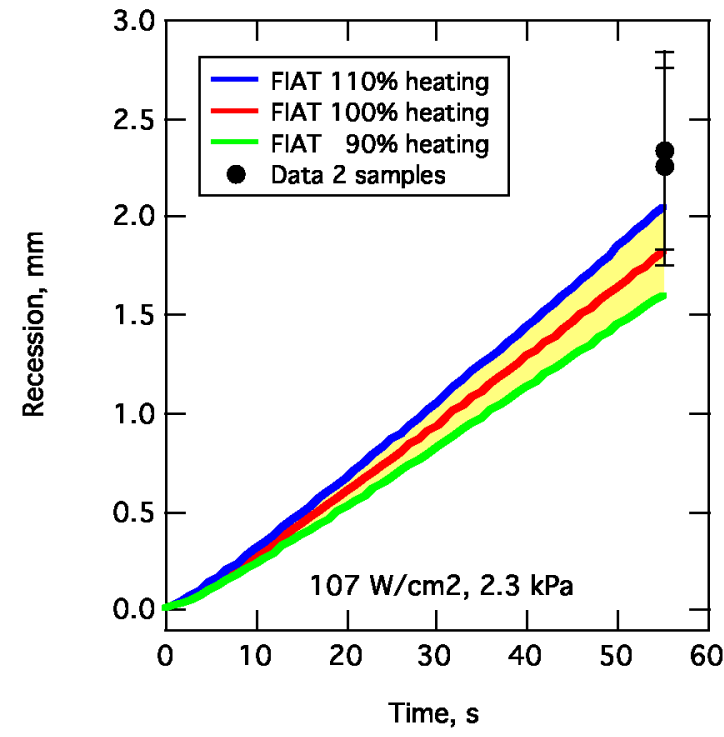

Figure 12a. Measured and predicted centerline recession for case 1 with environmental uncertainty.

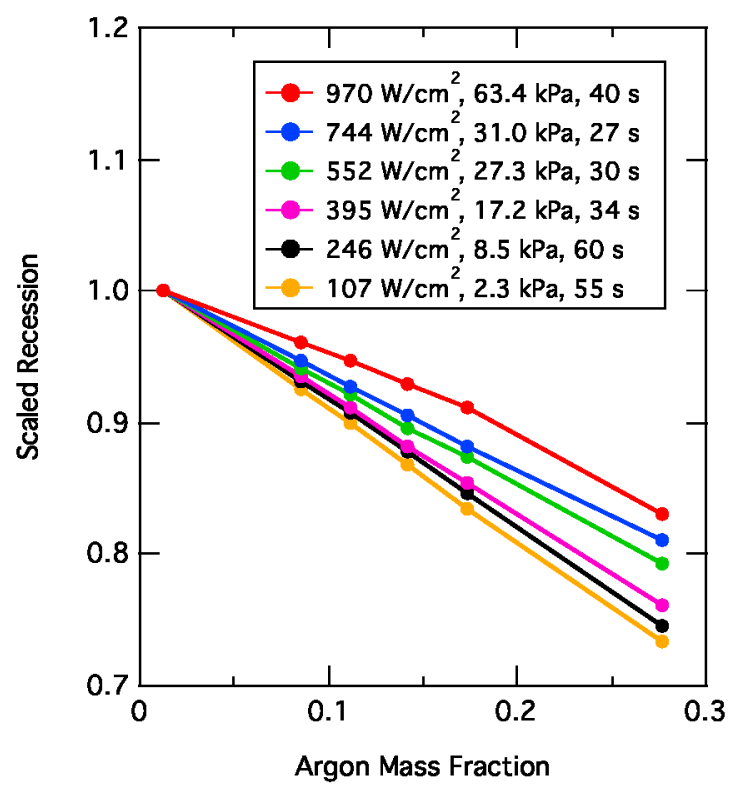

Figure $11 b$. Effect of argon fraction on scaled recession for nominal (100\%) heating.

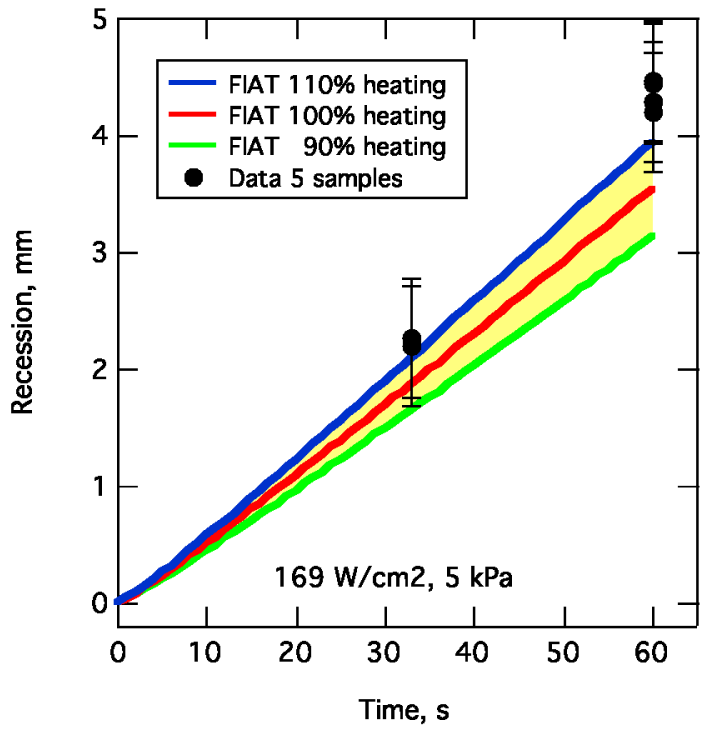

Figure 12b. Measured and predicted centerline recession for case 2 with environmental uncertainty. 


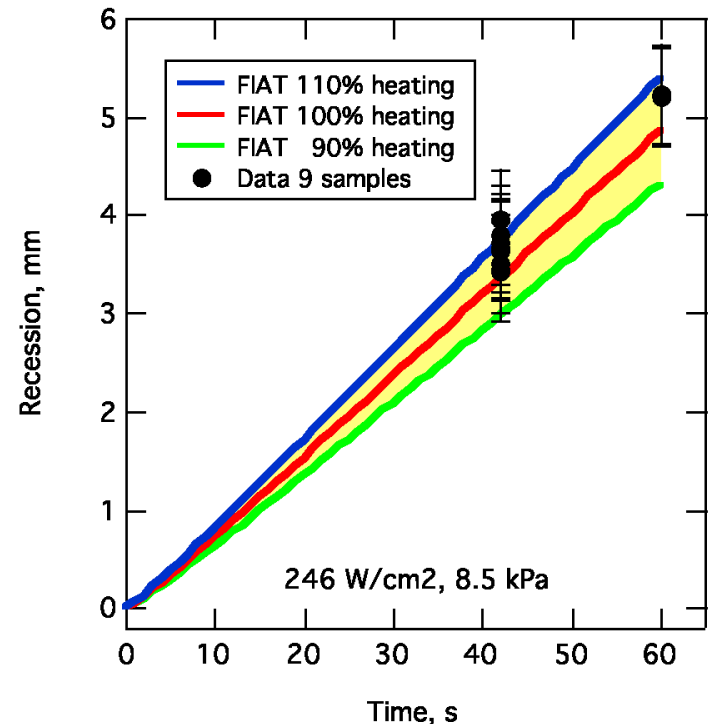

Figure 12c. Measured and predicted centerline recession for case 3 with environmental uncertainty.

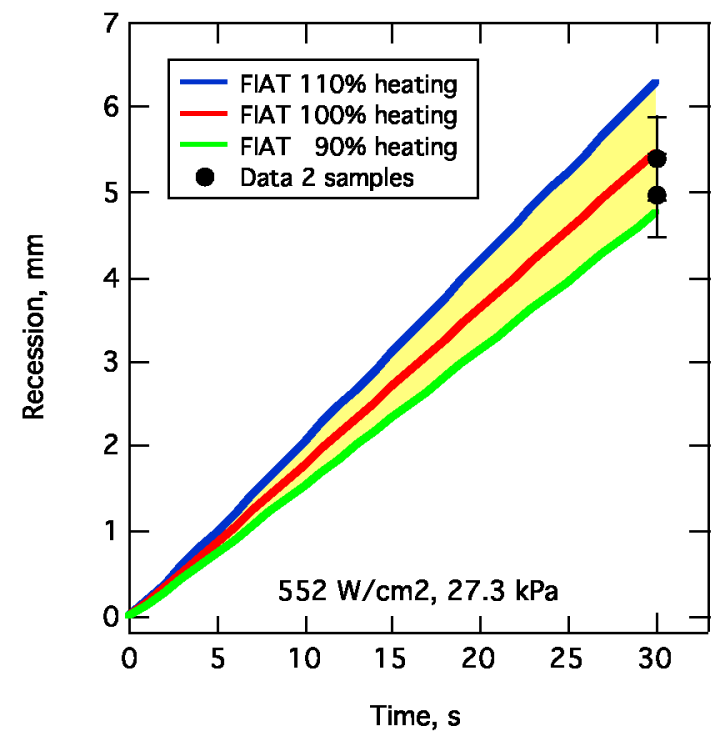

Figure 12e. Measured and predicted centerline recession for case 5 with environmental uncertainty.

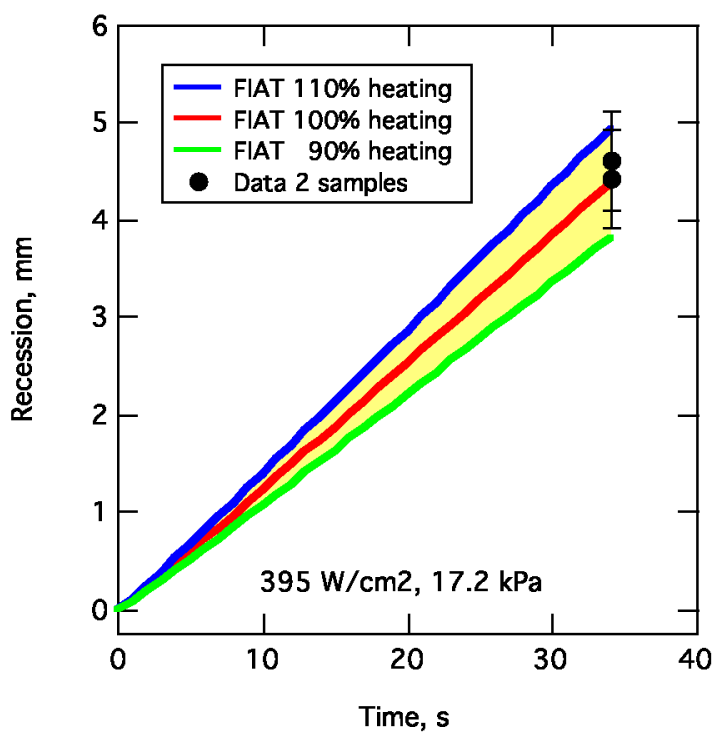

Figure 12d. Measured and predicted centerline recession for case 4 with environmental uncertainty.

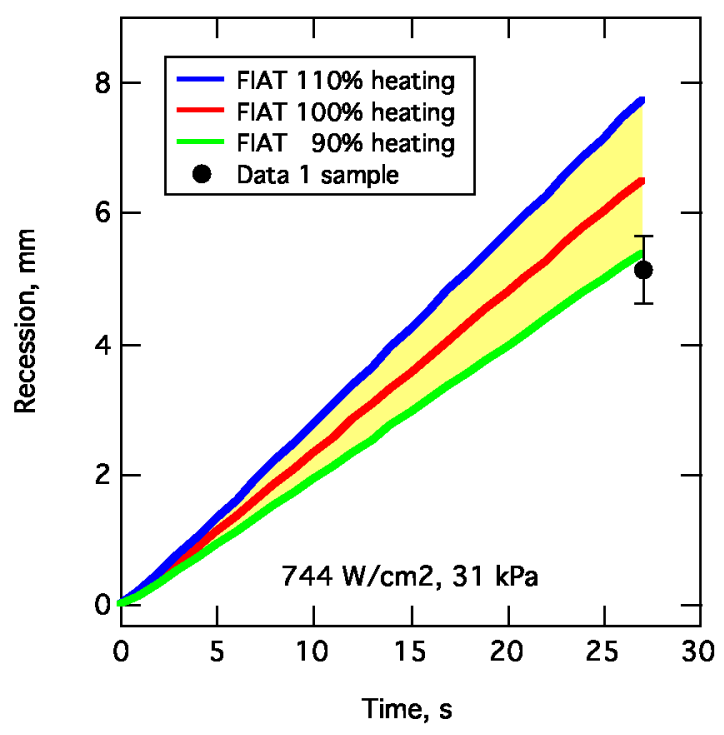

Figure 12f. Measured and predicted centerline recession for case 6 with environmental uncertainty. 


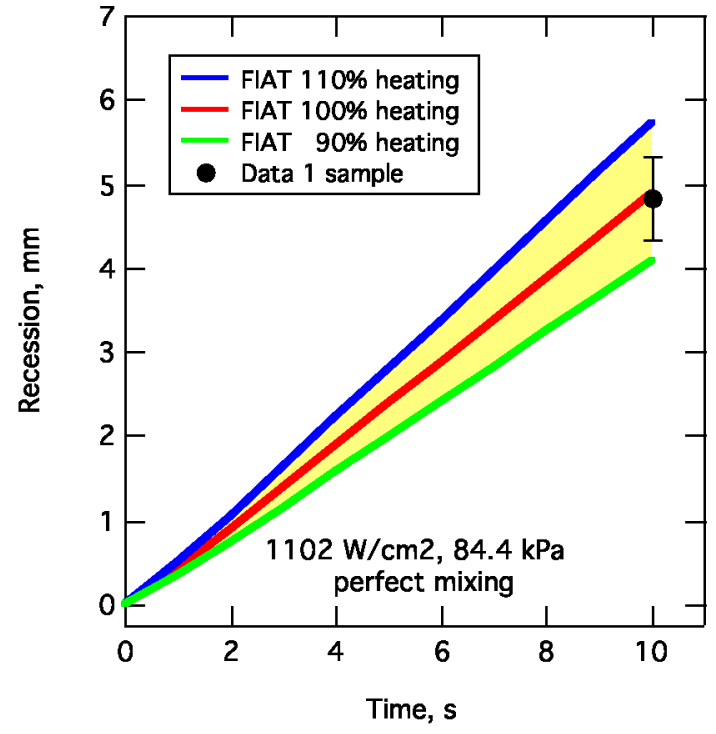

Figure 12g. Measured and predicted centerline recession for case 7 with environmental uncertainty.

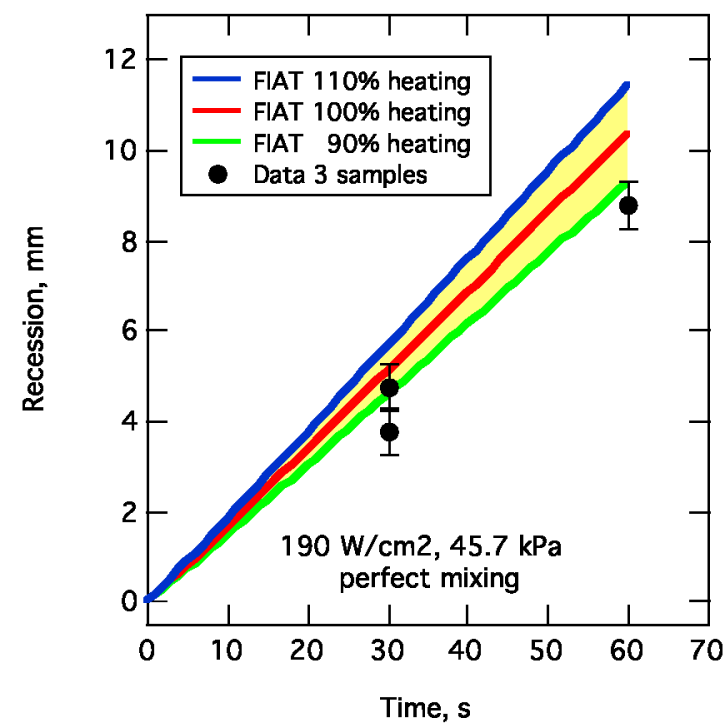

Figure 14a. Measured and predicted centerline recession for condition 5 with environmental uncertainty and perfect add-air mixing ( $8 \%$ argon).

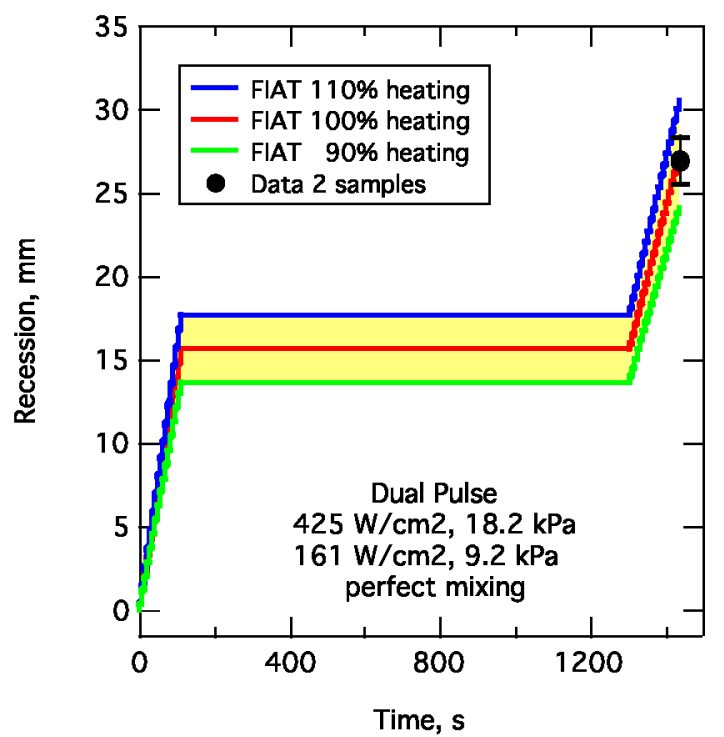

Figure 13. Measured and predicted centerline recession for condition 18 with environmental uncertainty.

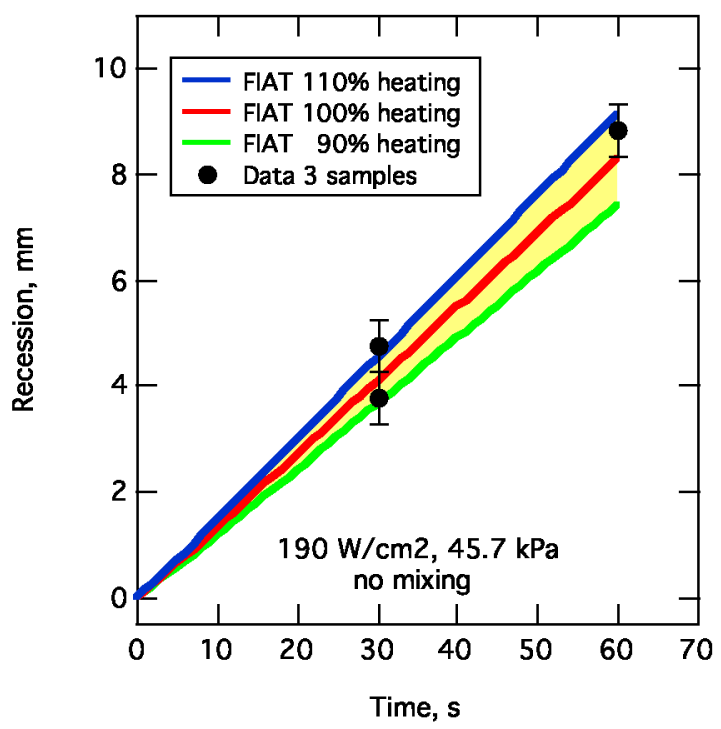

Figure 14b. Measured and predicted centerline recession for condition 5 with environmental uncertainty and no add-air mixing (26\% argon). 


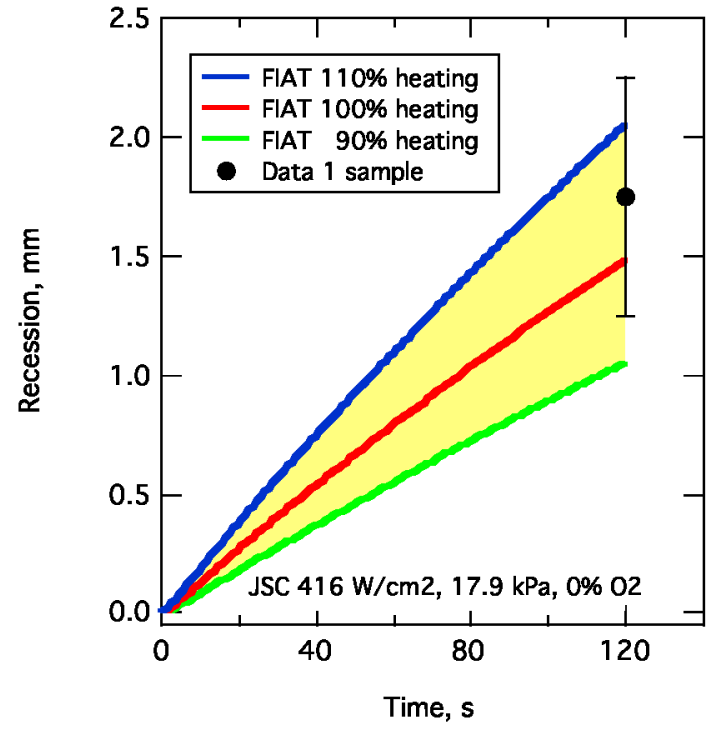

Figure 15a. Measured and predicted centerline recession for condition 19 with environmental uncertainty.

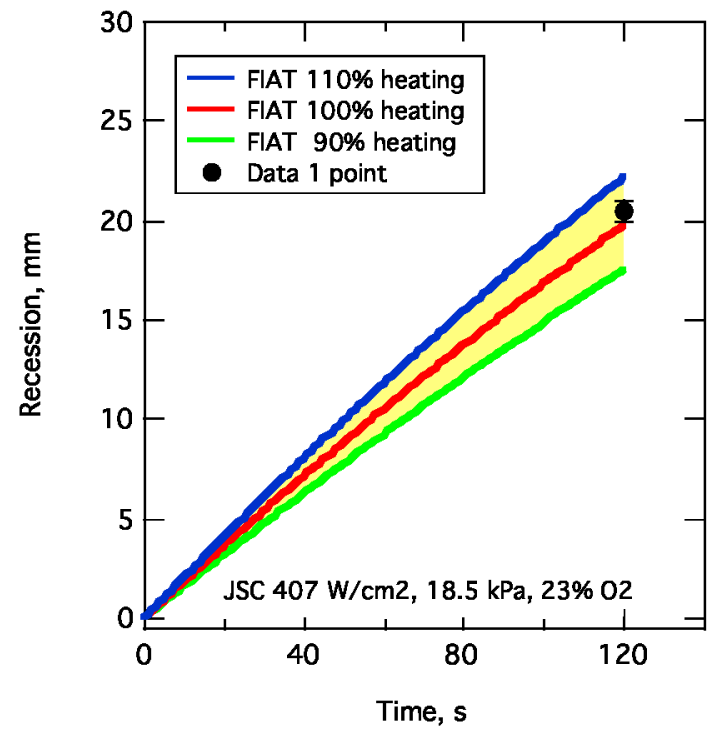

Figure 15c. Measured and predicted centerline recession for condition 21 with environmental uncertainty.

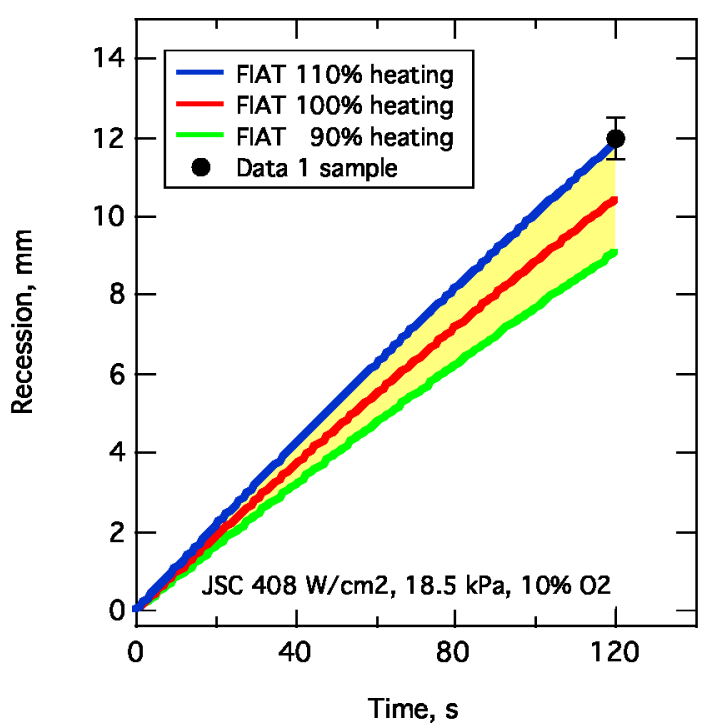

Figure 15b. Measured and predicted centerline recession for condition 20 with environmental uncertainty.

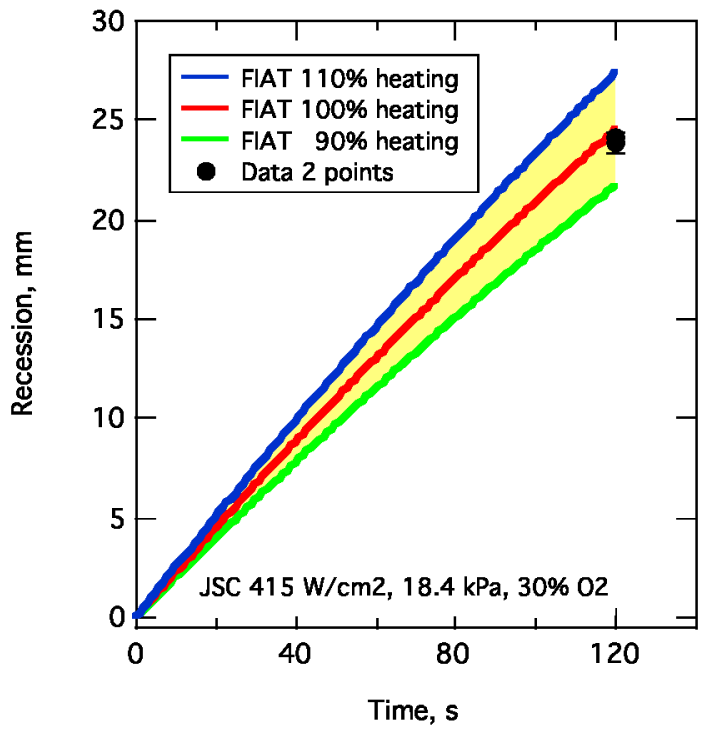

Figure 15d. Measured and predicted centerline recession for condition 22 with environmental uncertainty. 


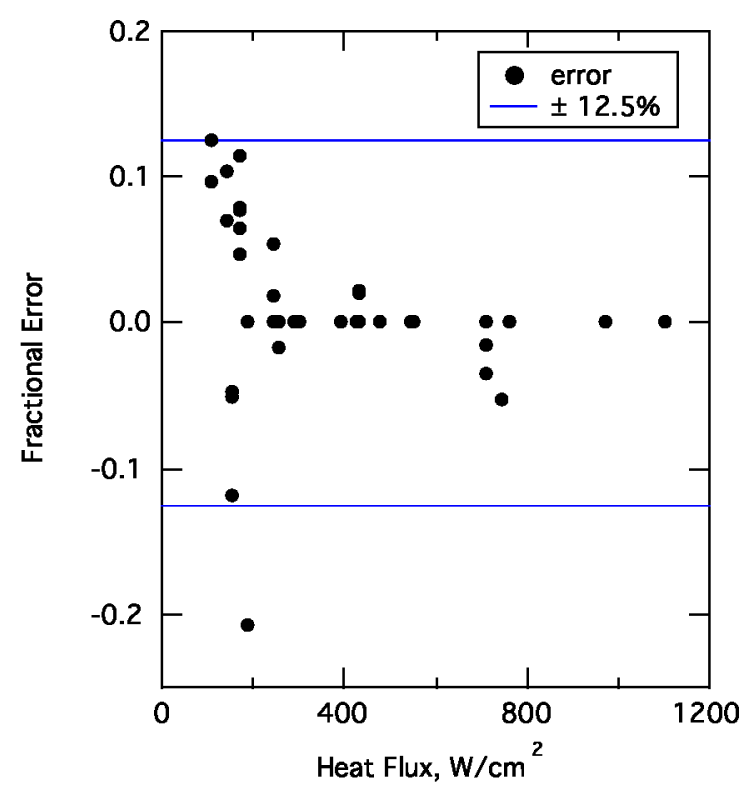

Figure 16a. Fractional error in recession prediction as a function of heat flux for all models in Tables 3 and 4.

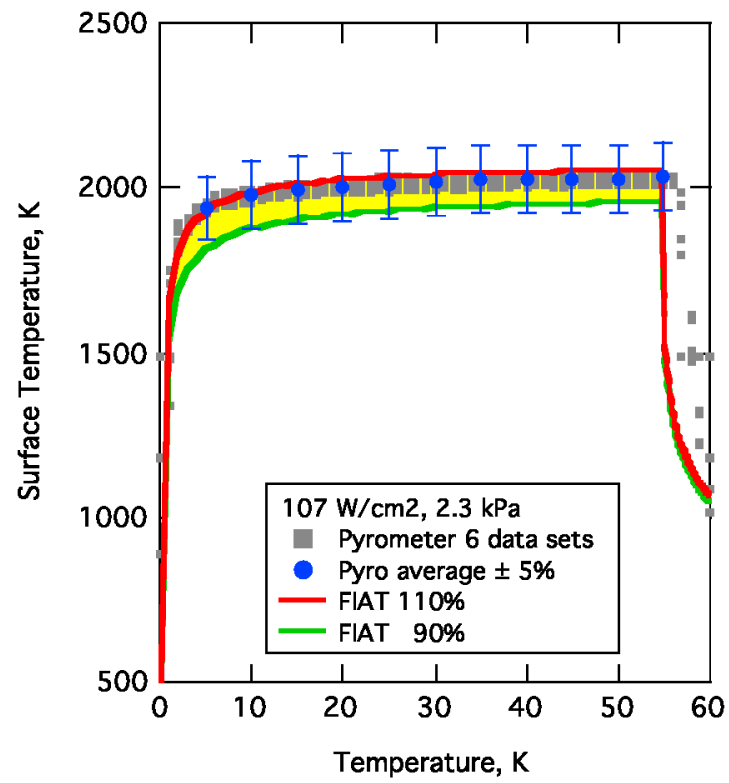

Figure 17a. Measured and predicted surface temperature for case 1 with environmental uncertainty.

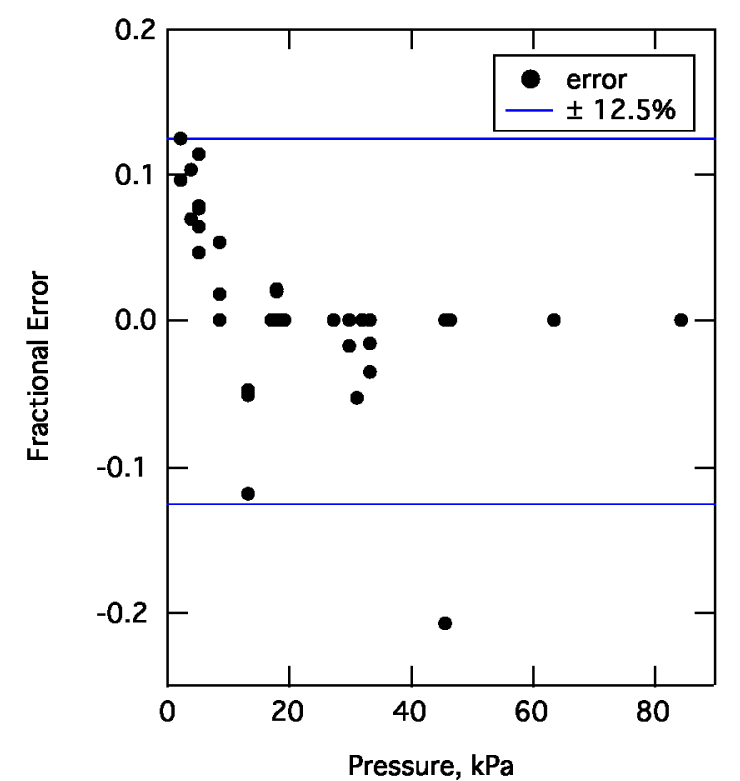

Figure 16b. Fractional error in recession prediction as a function of pressure for all models in Tables 3 and 4.

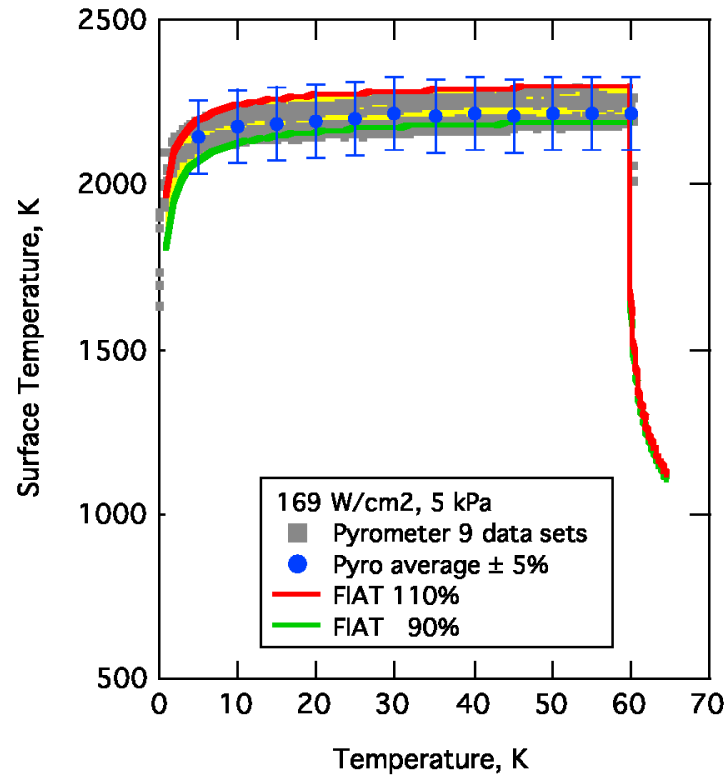

Figure $17 \mathrm{~b}$. Measured and predicted surface temperature for case 2 with environmental uncertainty. 


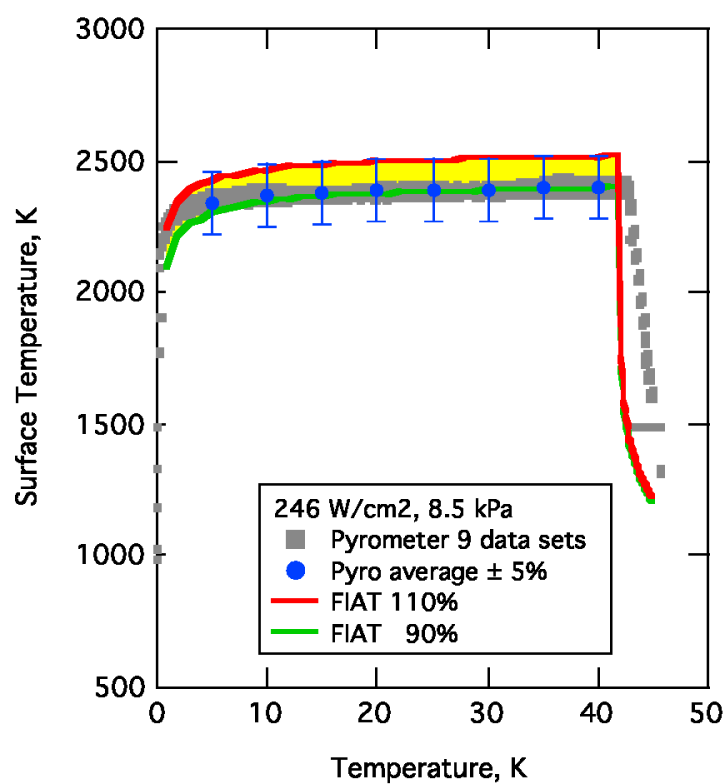

Figure 17c. Measured and predicted surface temperature for case 3 with environmental uncertainty.

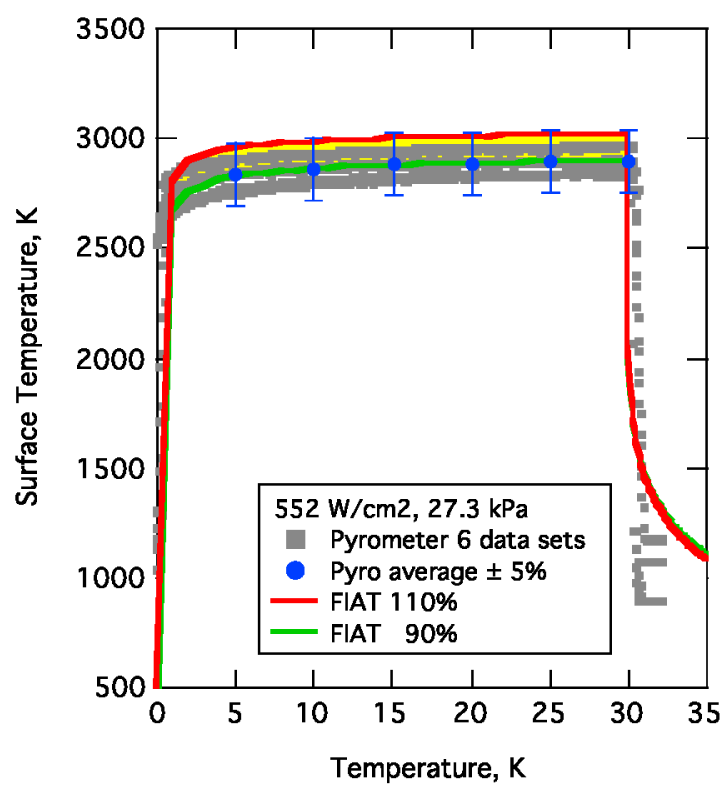

Figure 17e. Measured and predicted surface temperature for case 5 with environmental uncertainty.

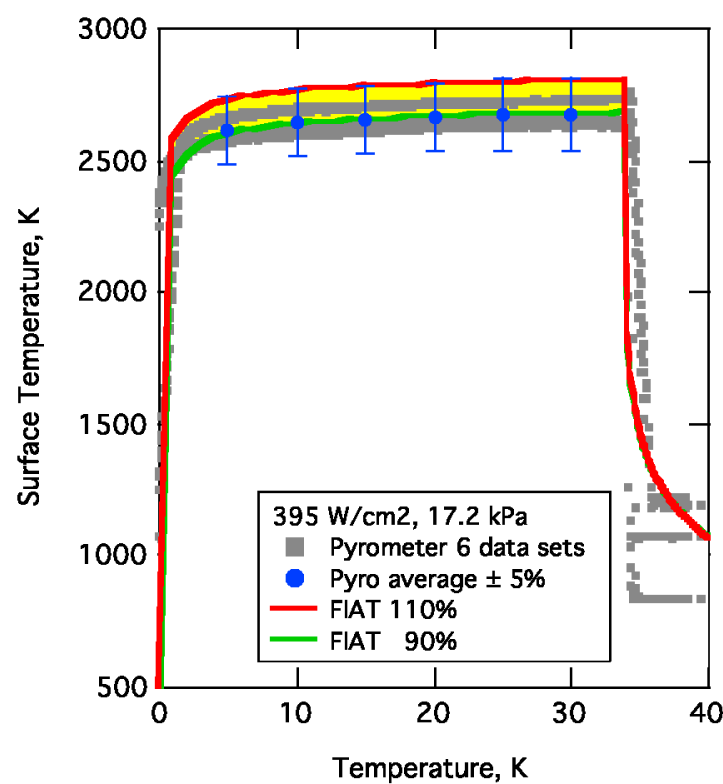

Figure 17d. Measured and predicted surface temperature for case 4 with environmental uncertainty.

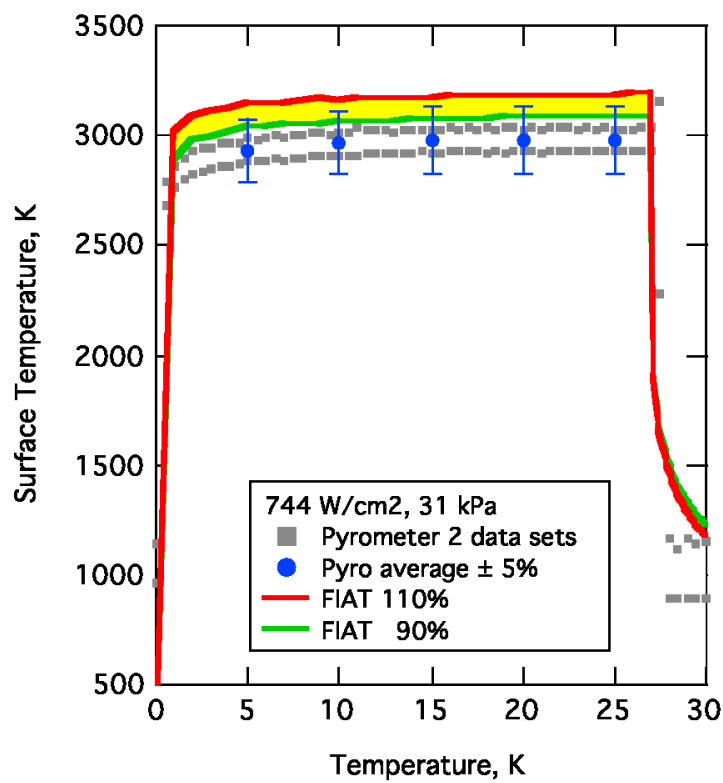

Figure 17f. Measured and predicted surface temperature for case 6 with environmental uncertainty. 


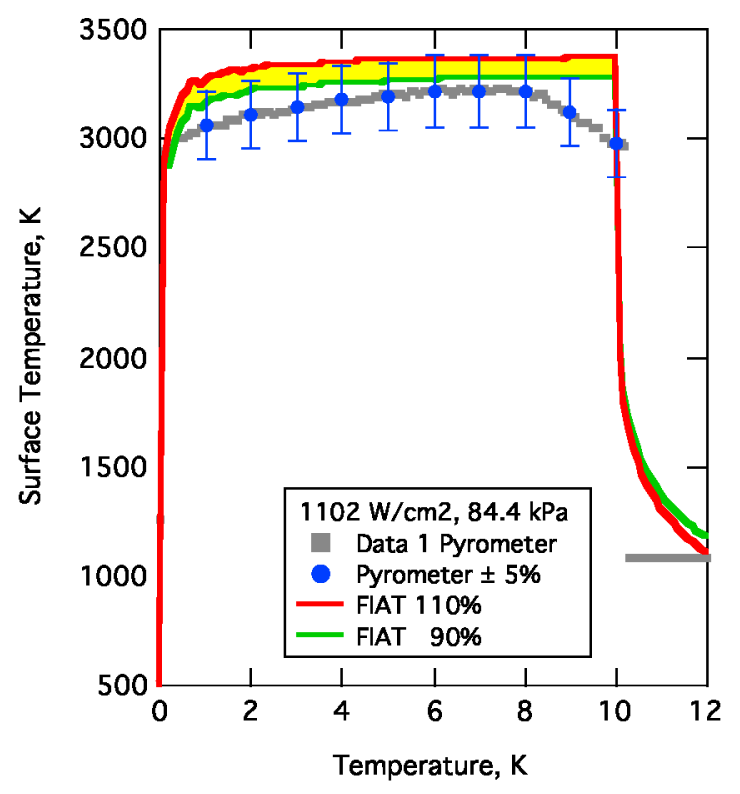

Figure 17g. Measured and predicted surface temperature for case 7 with environmental uncertainty.

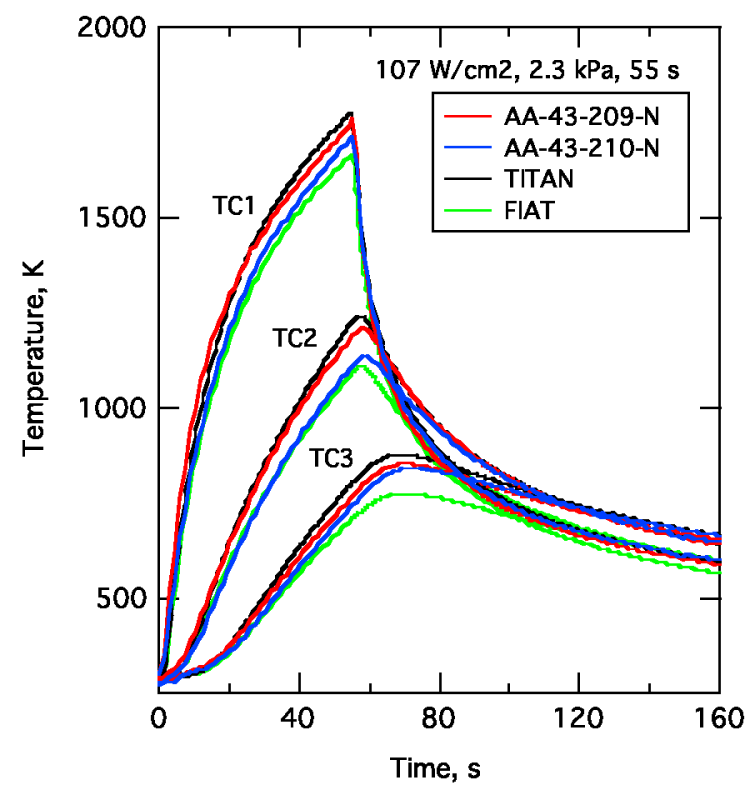

Figure 19a. Measured and predicted in-depth temperatures for case 1 thermocouples 1 to 3.

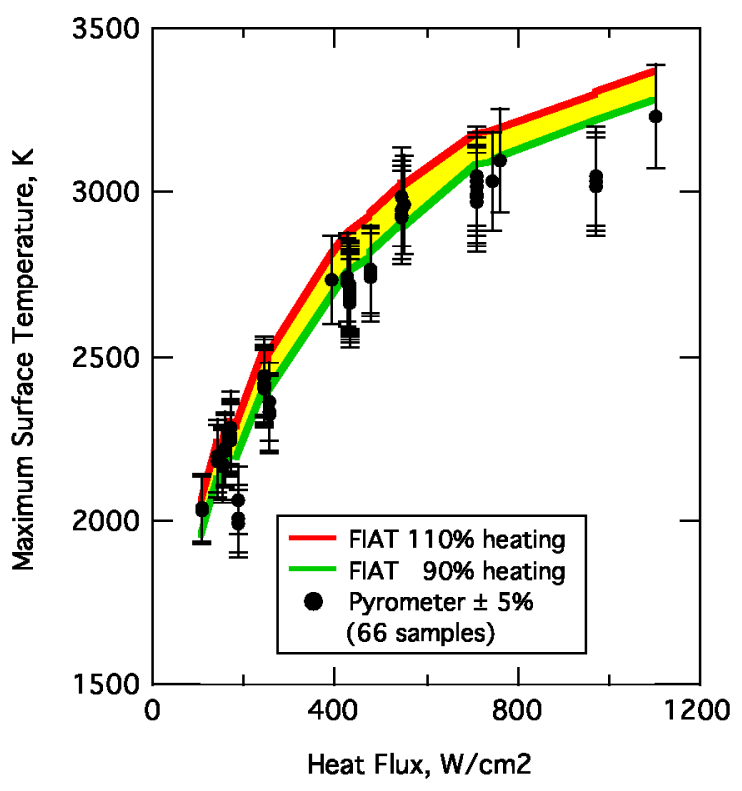

Figure 18. Measured and predicted peak surface temperature for all conditions.

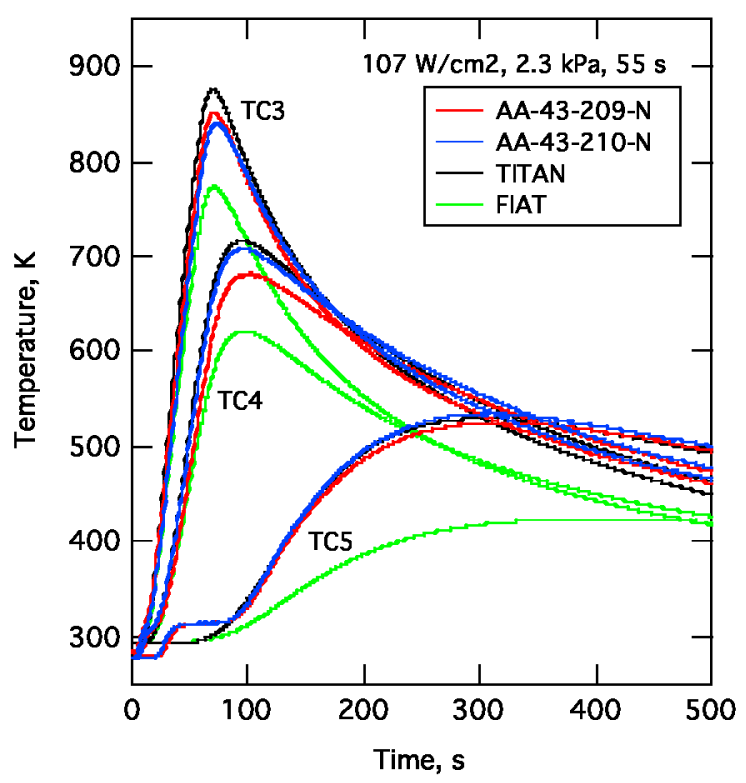

Figure 19b. Measured and predicted in-depth temperatures for case 1 thermocouples 3 to 5 . 


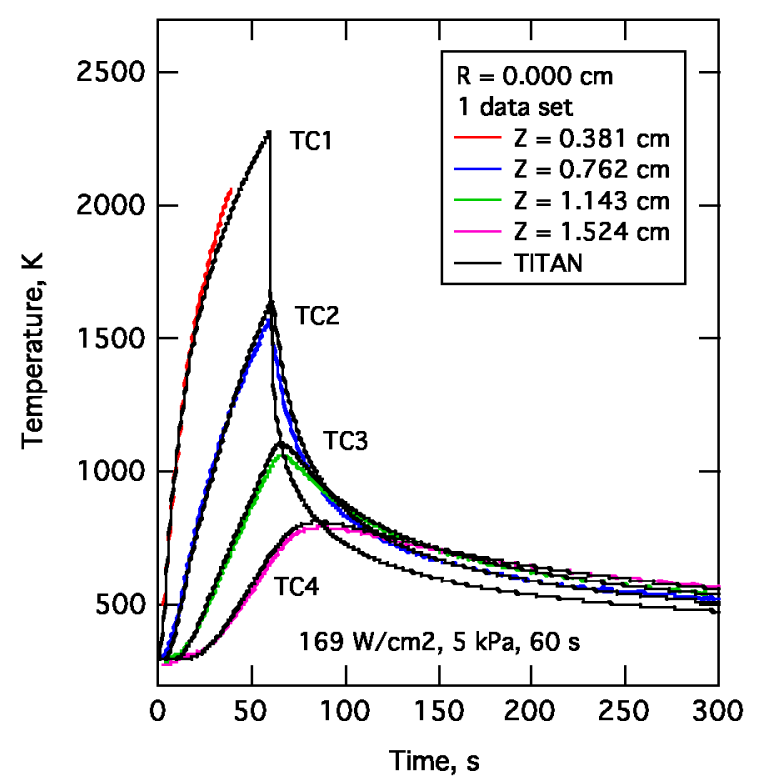

Figure 20a. Measured and predicted in-depth temperatures for case 2 axial thermocouples 1 to 4 .

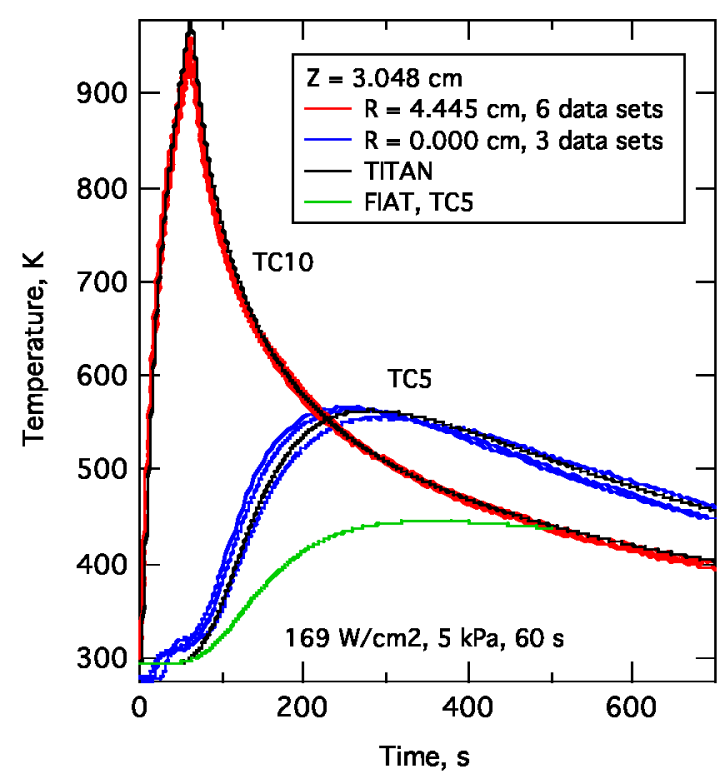

Figure 20c. Measured and predicted in-depth temperatures for case 2 thermocouples at an initial depth of $2.286 \mathrm{~cm}$.

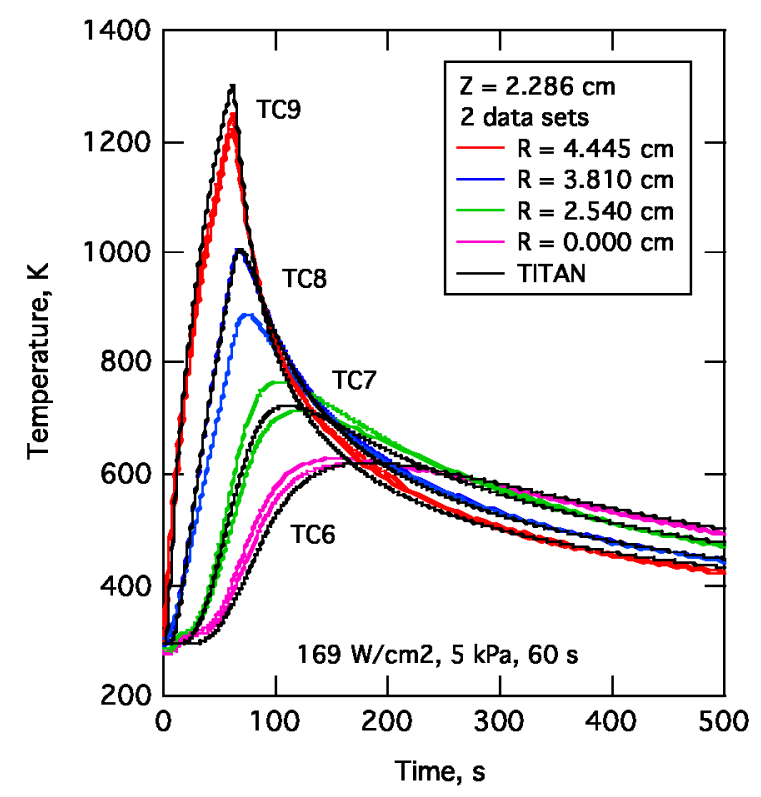

Figure 20b. Measured and predicted in-depth temperatures for case 2 thermocouples at an initial depth of $2.286 \mathrm{~cm}$.

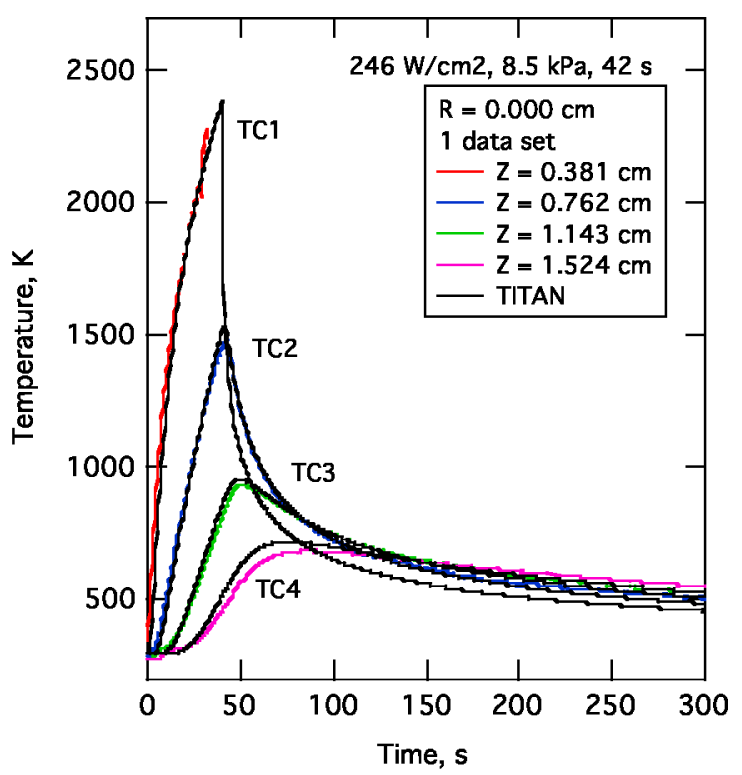

Figure 21a. Measured and predicted in-depth temperatures for case 3 axial thermocouples 1 to 4 . 


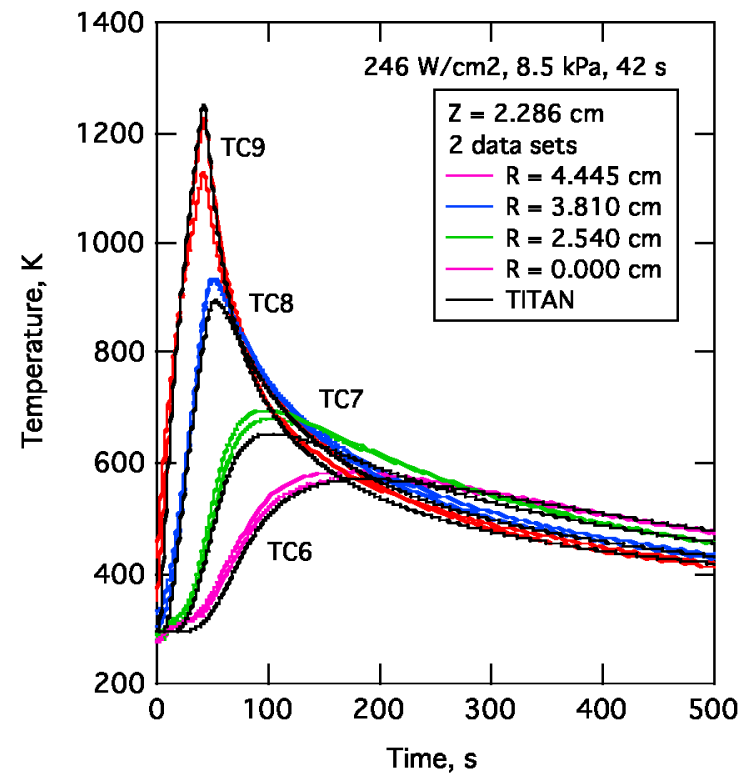

Figure $21 \mathrm{~b}$. Measured and predicted in-depth temperatures for case 3 thermocouples at an initial depth of $2.286 \mathrm{~cm}$.

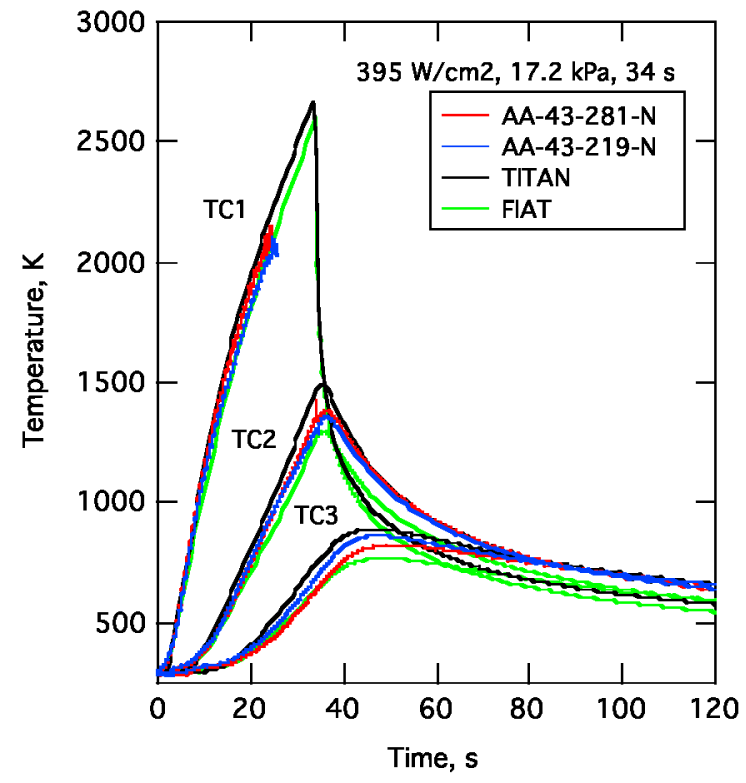

Figure 22a. Measured and predicted in-depth temperatures for case 4 thermocouples 1 to 3.

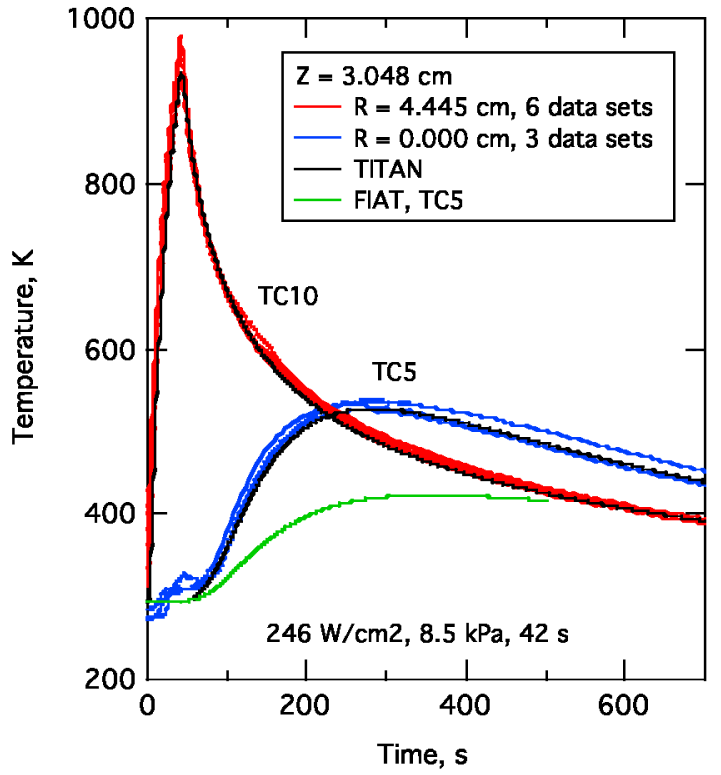

Figure 21c. Measured and predicted in-depth temperatures for case 3 thermocouples at an initial depth of $2.286 \mathrm{~cm}$.

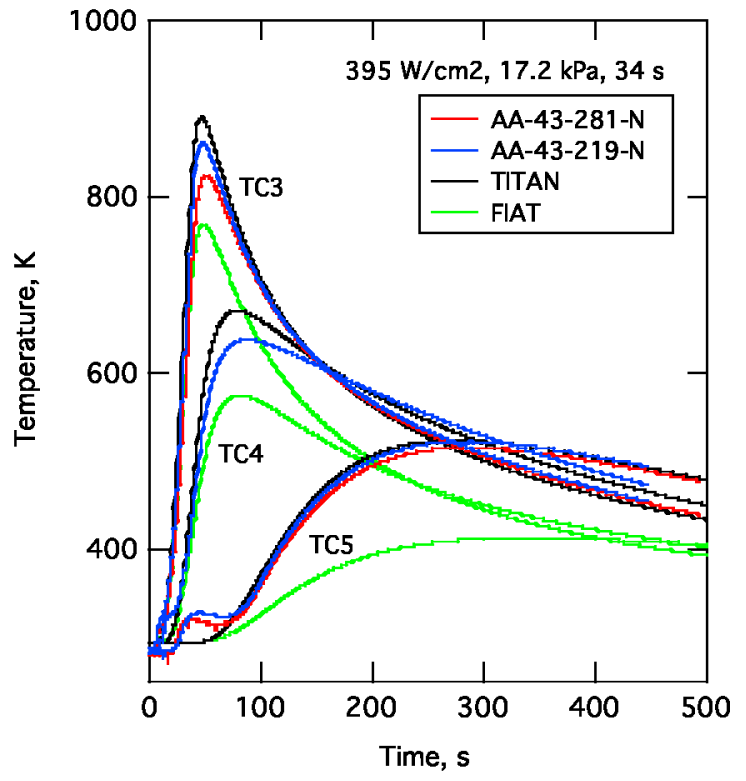

Figure 22b. Measured and predicted in-depth temperatures for case 4 thermocouples 3 to 5 . 


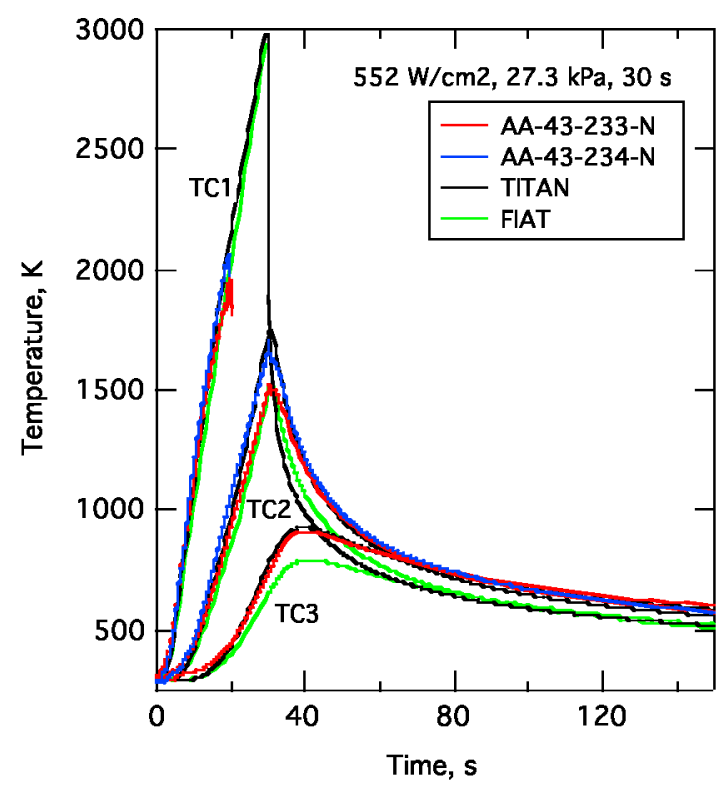

Figure 23a. Measured and predicted in-depth temperatures for case 5 thermocouples 1 to 3.

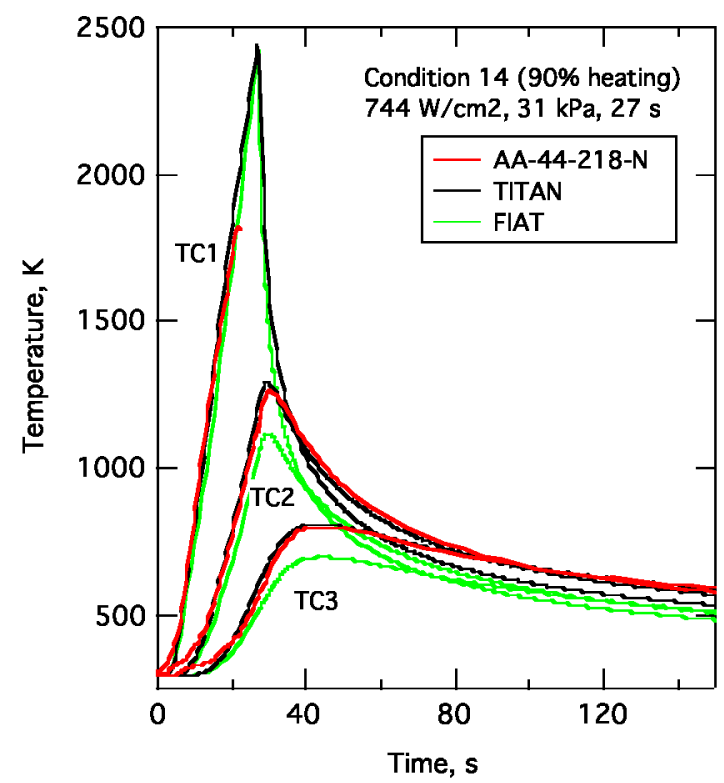

Figure 24a. Measured and predicted in-depth temperatures for case 6 thermocouples 1 to 3 with $90 \%$ scaling.

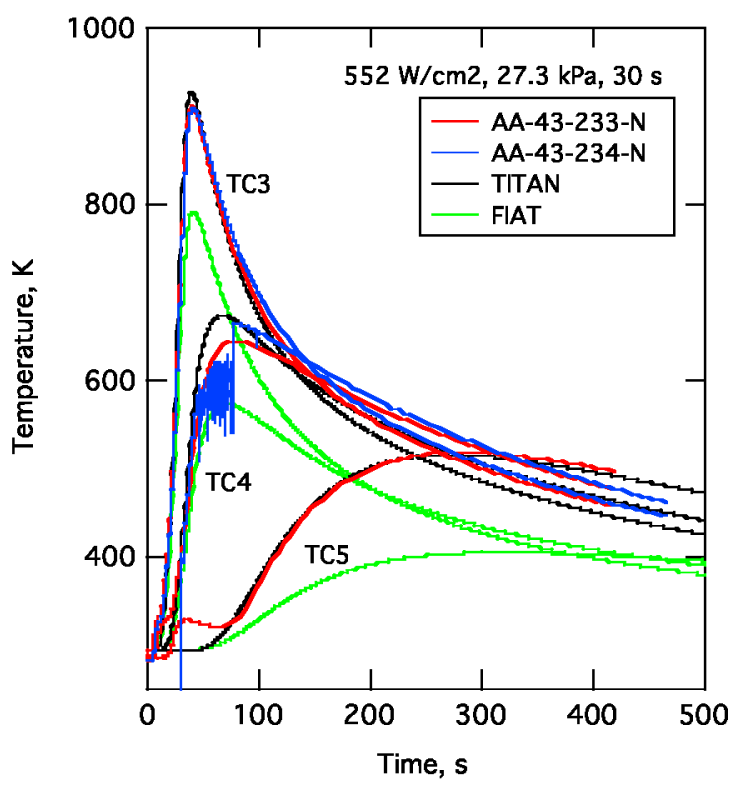

Figure 23b. Measured and predicted in-depth temperatures for case 5 thermocouples 3 to 5 .

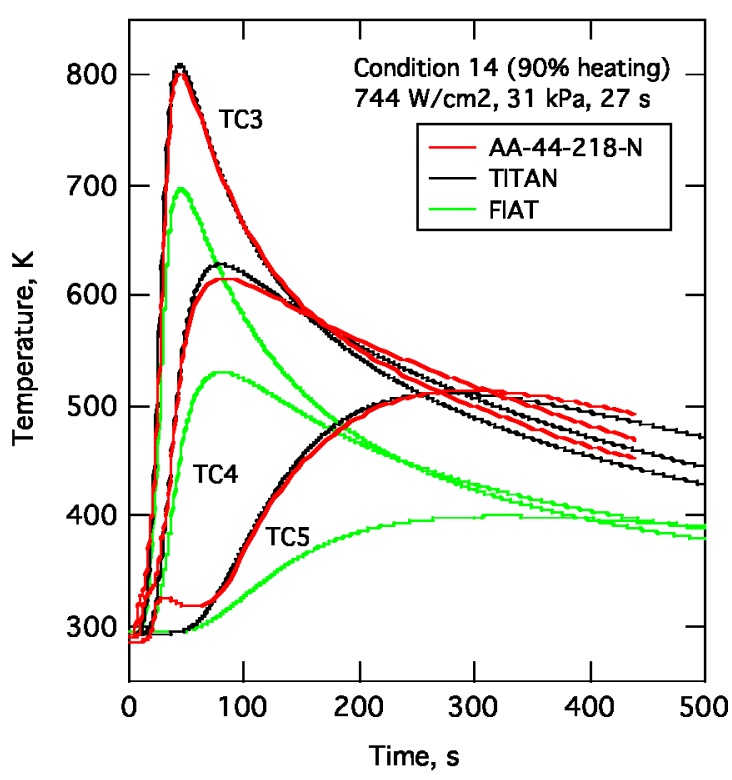

Figure 24b. Measured and predicted in-depth temperatures for case 6 thermocouples 3 to 5 with $90 \%$ scaling. 
Paper AIAA-2009-0262 for the 47th AIAA Aerospace Sciences Meeting, Orlando, Florida, 5-8 January 2009.

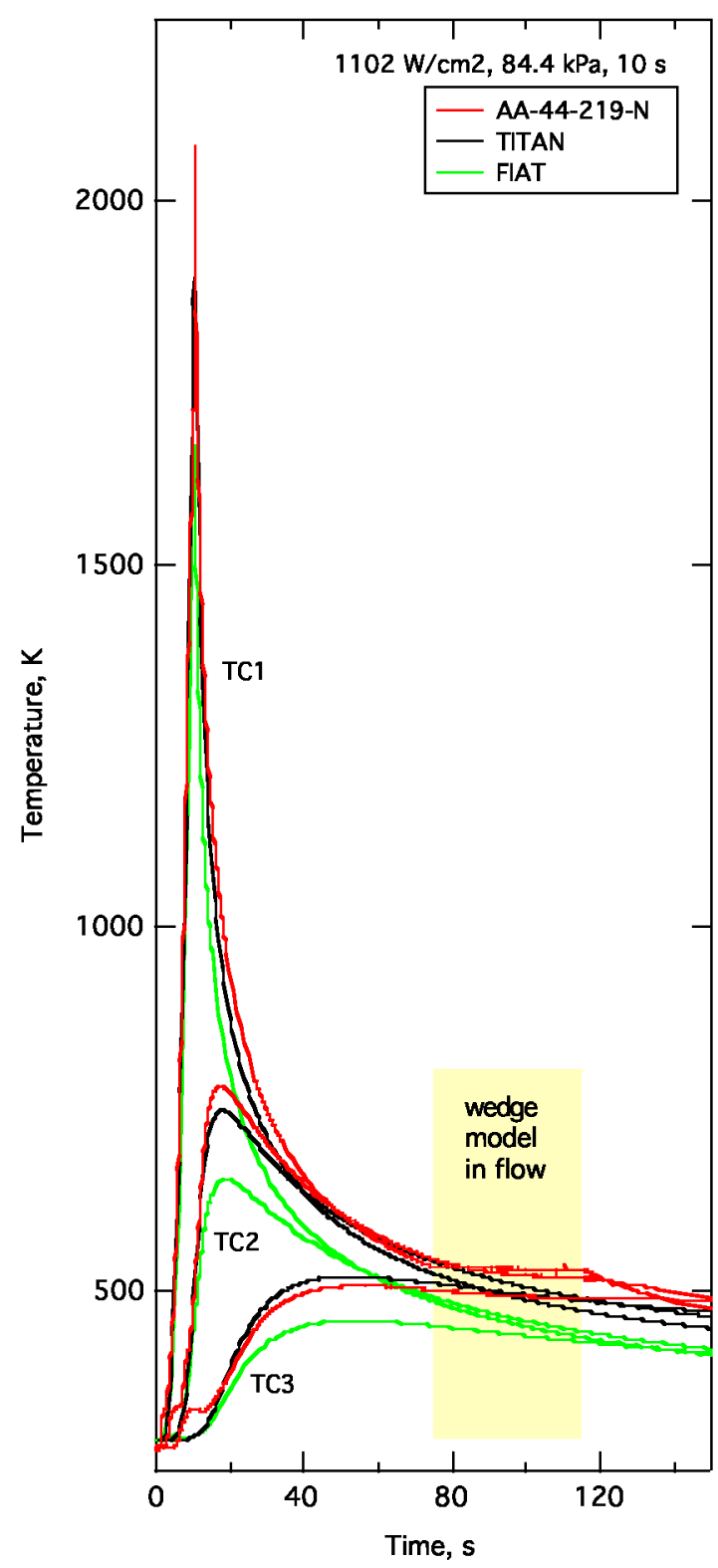

Figure 25a. Measured and predicted in-depth temperatures for case 7 thermocouples 1 to 3.

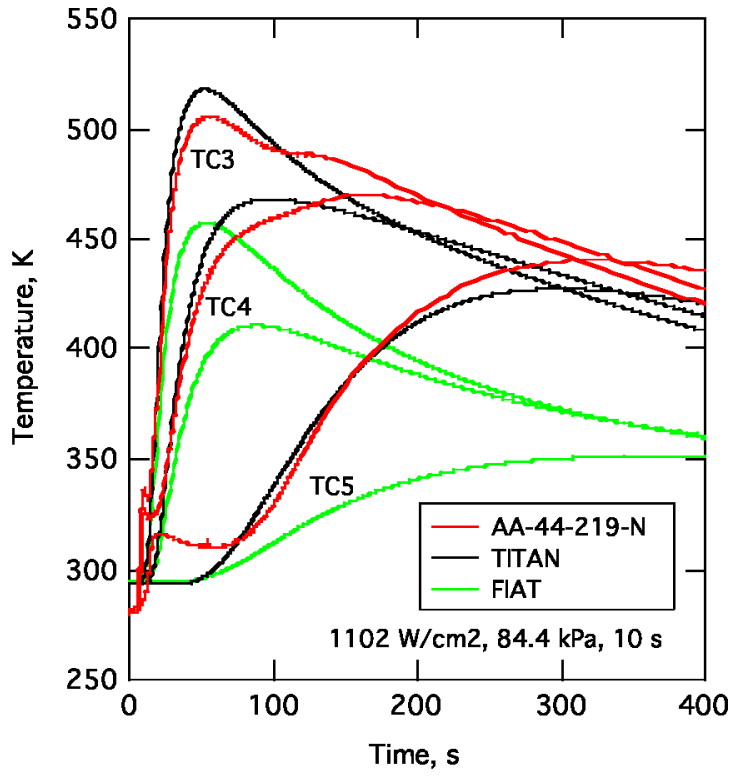

Figure 25b. Measured and predicted in-depth temperatures for case 7 thermocouples 3 to 5 . 


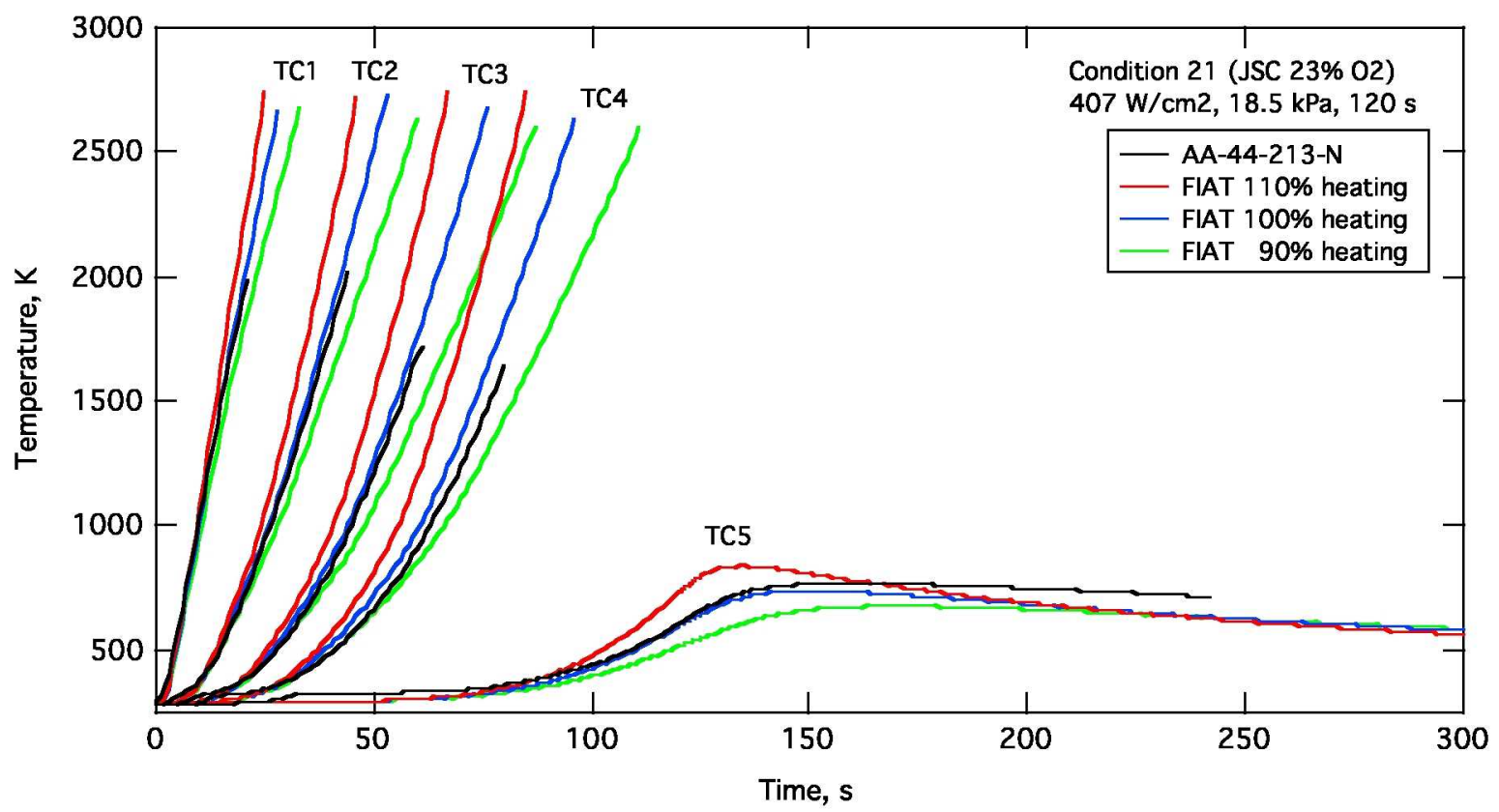

Figure 26. Measured and predicted in-depth temperatures for thermocouples 1 to 5 at condition 21.

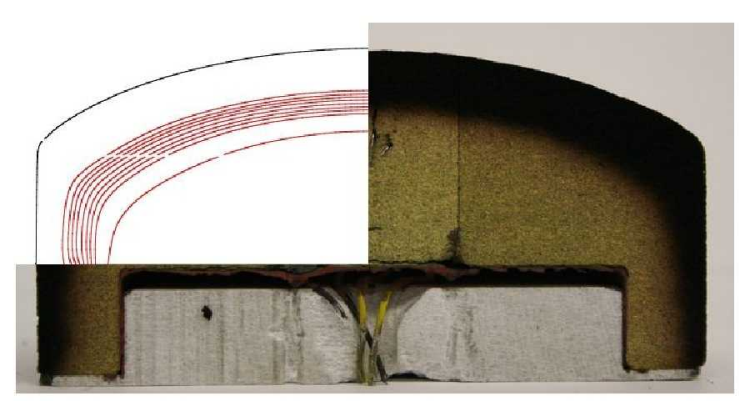

Figure 27a. Comparison of predicted shape and density contours with model cross-section for case 1 at $107 \mathrm{~W} / \mathrm{cm}^{2}$.

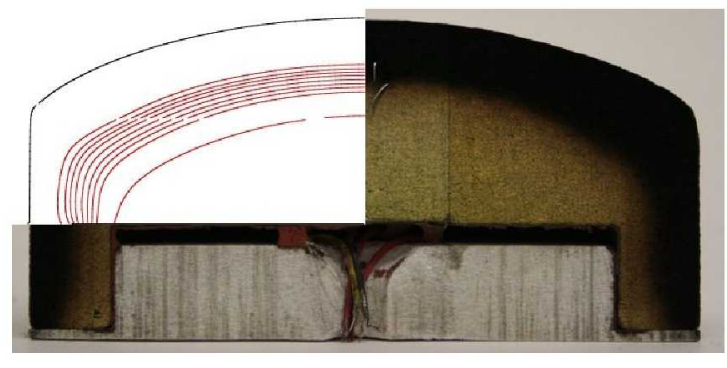

Figure 27b. Comparison of predicted shape and density contours with model cross-section for case 2 at 169 $\mathbf{W} / \mathrm{cm}^{2}$. 


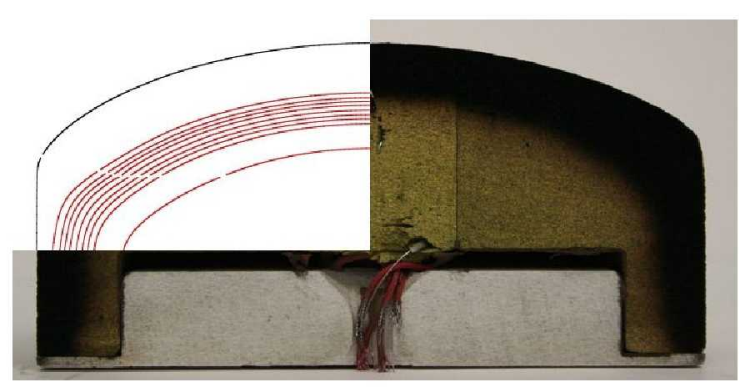

Figure 27c. Comparison of predicted shape and density contours with model cross-section for case 3 at $246 \mathrm{~W} / \mathrm{cm}^{2}$.

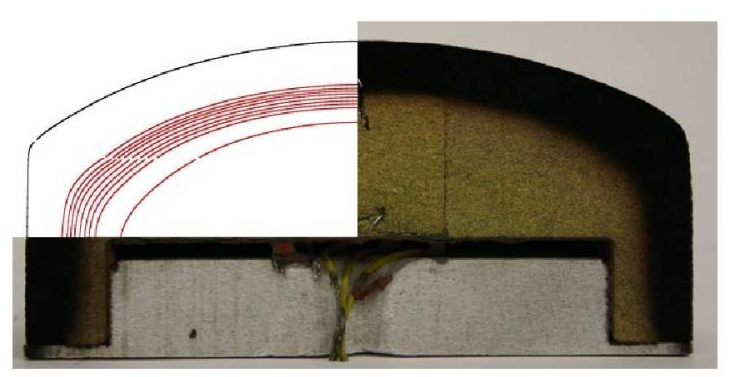

Figure 27e. Comparison of predicted shape and density contours with model cross-section for case 5 at $552 \mathrm{~W} / \mathrm{cm}^{2}$.

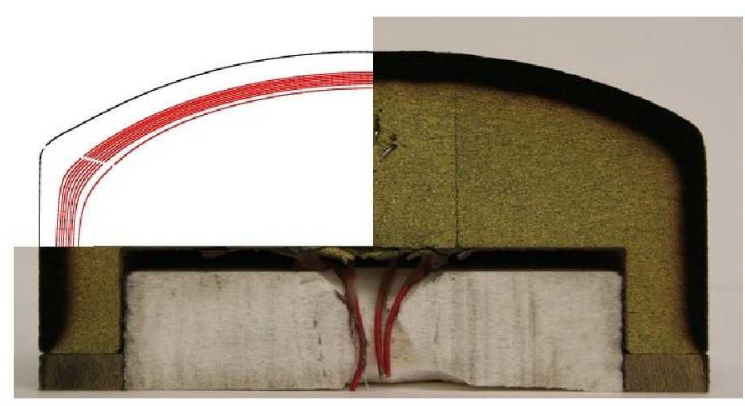

Figure 27g. Comparison of predicted shape and density contours with model cross-section for case 7 at $1102 \mathrm{~W} / \mathrm{cm}^{2}$.

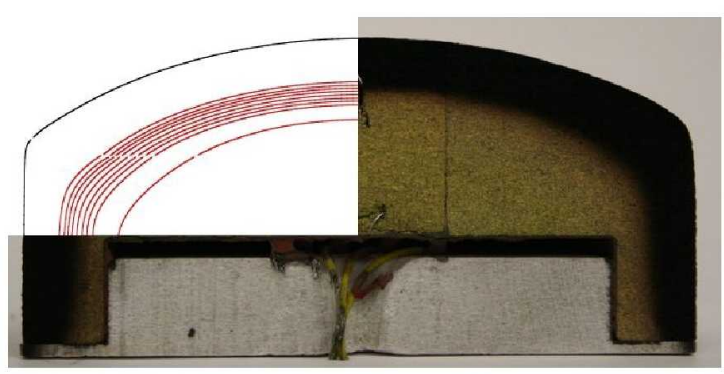

Figure 27d. Comparison of predicted shape and density contours with model cross-section for case 4 at 395 $\mathbf{W} / \mathrm{cm}^{2}$.

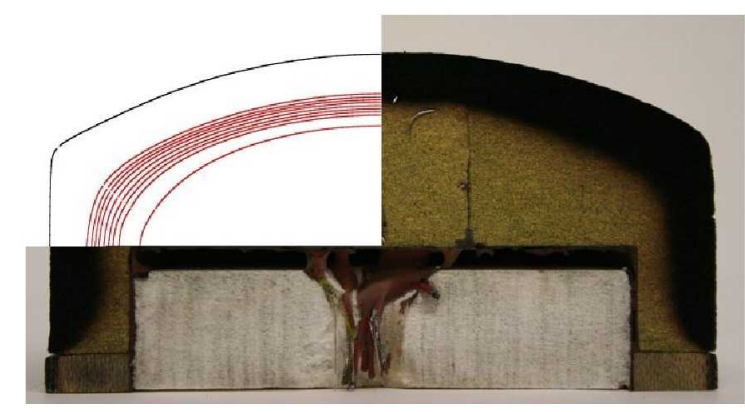

Figure 27f. Comparison of predicted shape and density contours with model cross-section for case 6 with $90 \%$ scaling of $744 \mathrm{~W} / \mathrm{cm}^{2}$. 